\title{
Hes5 Expression in the Postnatal and Adult Mouse Inner Ear and the Drug-Damaged Cochlea
}

\author{
Byron H. Hartman, ${ }^{1}$ Onur Basak, ${ }^{2}$ Branden R. Nelson, ${ }^{1}$ Verdon Taylor, ${ }^{2}$ \\ Olivia Bermingham-McDonogh, ${ }^{1,3}$ and Thomas A. ReH ${ }^{1}$ \\ ${ }^{1}$ Department of Biological Structure, University of Washington, 815 Mercer Street, Box 357420, Seattle, WA 98195, USA \\ ${ }^{2}$ Department of Molecular Embryology, Max-Planck Institute of Immunobiology, Stubeweg 51, 79108, Freiburg, Germany \\ ${ }^{3}$ Virginia Merrill Bloedel Hearing Research Center at the University of Washington, Seattle, WA 98195, USA
}

Received: 14 November 2008; Accepted: 9 February 2009; Online publication: 17 April 2009

\begin{abstract}
The Notch signaling pathway is known to have multiple roles during development of the inner ear. Notch signaling activates transcription of Hes5, a homologue of Drosophila hairy and enhancer of split, which encodes a basic helix-loop-helix transcriptional repressor. Previous studies have shown that Hes 5 is expressed in the cochlea during embryonic development, and loss of Hes 5 leads to overproduction of auditory and vestibular hair cells. However, due to technical limitations and inconsistency between previous reports, the precise spatial and temporal pattern of Hes 5 expression in the postnatal and adult inner ear has remained unclear. In this study, we use Hes5GFP transgenic mice and in situ hybridization to report the expression pattern of Hes 5 in the inner ear. We find that Hes 5 is expressed in the developing auditory epithelium of the cochlea beginning at embryonic day 14.5 (E14.5), becomes restricted to a particular subset of cochlear supporting cells, is downregulated in the postnatal cochlea, and is not present in adults. In the vestibular system, we detect Hes 5 in developing supporting cells as early as E12.5 and find that Hes 5 expression is maintained in some adult vestibular supporting cells. In order to determine the effect of hair cell damage on Notch signaling in the cochlea, we damaged cochlear hair
\end{abstract}

Correspondence to: Thomas A. Reh · Department of Biological Structure - University of Washington - Box 357420, Seattle, WA 98195, USA. Telephone: +1-206-5435069; fax: +1-206-5431524; email: tomreh@u.washington.edu

Correspondence to: Olivia Bermingham-McDonogh - Department of Biological Structure - University of Washington - 815 Mercer Street, Seattle, WA 98109, USA. Telephone: +1-206-6164652; fax: +1-2065431524; email: oliviab@u.washington.edu cells of adult Hes5-GFP mice in vivo using injection of kanamycin and furosemide. Although outer hair cells were killed in treated animals and supporting cells were still present after damage, supporting cells did not upregulate Hes5-GFP in the damaged cochlea. Therefore, absence of Notch-Hes5 signaling in the normal and damaged adult cochlea is correlated with lack of regeneration potential, while its presence in the neonatal cochlea and adult vestibular epithelia is associated with greater capacity for plasticity or regeneration in these tissues; which suggests that this pathway may be involved in regulating regenerative potential.

Keywords: development, regeneration, supporting cell, hair cell, Notch, bHLH

\section{INTRODUCTION}

The mammalian inner ear sensory epithelia are composed of mechanosensory hair cells and nonsensory supporting cells. Auditory hair cells in the cochlea detect sound, while hair cells in the five vestibular organs detect signals associated with angular and linear movements of the head. Supporting cells share a common progenitor with hair cells (Fekete et al. 1998) and are a morphologically diverse population of epithelial cells that surround hair cells and provide structural and functional support.

Auditory hair cells are susceptible to damage due to a variety of environmental factors, and hair cell death is irreversible in mammals. However, birds and other non-mammalian vertebrates have been shown to be capable of hair cell regeneration and subse- 
quent gain of hearing after injury (for reviews, see Bermingham-McDonogh and Rubel 2003; Stone and Cotanche 2007; Oesterle and Stone 2008). In mammals, when damaged hair cells are extruded from the organ of Corti, supporting cells close the lesions and are reorganized, but they do not proliferate or transdifferentiate into new hair cells (Forge 1985; McDowell et al. 1989; Raphael and Altschuler 1991; Wu et al. 2001; Oesterle et al. 2008; Taylor et al. 2008). Little is known, however, about the changes in gene expression that do occur in mammalian supporting cells after hair cell damage and whether or not developmental mechanisms are reinitiated.

The Notch signaling pathway is a potent regulator of progenitors and stem cells and known to play several key roles during inner ear development: initially Notch activity is essential to establish prosensory domains (Daudet and Lewis 2005; Brooker et al. 2006; Kiernan et al. 2006; Daudet et al. 2007; Hayashi et al. 2008); subsequently, it is involved in establishing hair cell and supporting cell fates and patterning via "lateral inhibition" (Chitnis 1995; Lanford et al. 1999; Pickles and van Heumen 2000; Daudet and Lewis 2005; Kiernan et al. 2005a; Brooker et al. 2006). Notch signaling activates transcription of Hes5, a mammalian homologue of Drosophila hairy and enhancer of split, which encodes a basic helix-loop-helix transcriptional repressor (Kageyama and Ohtsuka 1999; Ohtsuka et al. 1999). Previous studies have shown that Hes 5 is expressed in subsets of cochlear and vestibular supporting cells during embryonic development (Shailam et al. 1999; Lanford et al. 2000; Zheng et al. 2000; Zine et al. 2001; Tang et al. 2006; Li et al. 2008); however, due to technical limitations and inconsistency between previous reports, the precise spatial and temporal pattern of Hes 5 expression in the developing and adult inner ear has remained unclear. In this study, we use Hes5-GFP transgenic mice (Basak and Taylor 2007) and in situ hybridization to report the expression pattern of Hes 5 in the inner ear through embryonic and postnatal development and in adults. We find that Hes5-GFP mimics the expression of Hes 5 and provides superior sensitivity and cellular resolution. In the cochlea, we describe the onset of Hes5-GFP expression at E14.5, its subsequent restriction during development to a subset of supporting cells where it persists through the first postnatal week, after which it becomes downregulated and is no longer expressed in the adult. In the vestibular system, we report that Hes5-GFP is expressed in supporting cells of all five vestibular organs during development and continues to be expressed in a subset of supporting cells in the adult.

In order to further understand the responsiveness of mammalian cochlear supporting cells to hair cell death, we induced hair cell damage in adult Hes5-GFP mice via injections of kanamycin and furosemide and analyzed cochlear tissues to see if Hes5-GFP is upregulated in the damaged cochlea. Although outer hair cells were rapidly lost in treated Hes5-GFP animals and supporting cells remained largely intact, there was no upregulation of Hes5-GFP. Thus, NotchHes5 signaling is not active in the mature cochlea under normal or damaged conditions. Taken together with earlier studies, our findings indicate that absence of Notch-Hes5 signaling in the adult cochlea is correlated with lack of regeneration potential, while its presence in the neonatal cochlea and adult vestibular epithelia is associated with greater capacity for plasticity or regeneration in these tissues, which suggests that this pathway may be involved in regulating regenerative potential.

\section{METHODS}

\section{Animals}

Mice were housed in the Department of Comparative Medicine, and the Institutional Animal Care and Use Committee approved experimental methods and animal care procedures. Hes5-GFP transgenic mice, on the C57/BL6 background, were generated as previously described (Basak and Taylor 2007) using a 3-kb portion of the Hes 5 gene, including $1.6 \mathrm{~kb}$ of the $5^{\prime}$ flanking region, with eGFP cloned into the translational start site. Mice were euthanized according to approved procedures: neonatal mice were killed by decapitation after $5 \mathrm{~min}$ of hypothermia; juvenile and adult mice were killed by anesthesia with $\mathrm{CO}_{2}$ followed by cardiac perfusion with $4 \%$ paraformaldehyde solution (PFA).

\section{Drug damage paradigm}

Outer hair cells were experimentally lesioned in adult mice (2-5 months old) as previously described (Oesterle et al. 2008). Briefly, mice were given single subcutaneous injections of kanamycin $(1000 \mathrm{mg} / \mathrm{kg}$ USP grade SigmaAldrich cat. no. K1637, in sterile phosphate-buffered saline, PBS) followed 30-45 min later by single intraperitoneal injections of furosemide $(400 \mathrm{mg} / \mathrm{kg}$, Hospira Inc., Lake Forest, IL, USA, cat. no. RL-1206). Animals were killed 2 or 4 days after the injections. Un-injected littermates were used as controls.

\section{Paraffin in situ hybridization}

Digoxigenin-labeled probe was in vitro transcribed from a linearized complementary DNA clone corresponding to Hes5 (BC103539, IMAGE: 40039948). Embryos were collected from timed pregnant Hes5-GFP or wild-type C57/BL6 mice and staged according to Kauffman 
(1992). For postnatal mice, postnatal day 0 (P0) was defined as the day of birth. In situ hybridization was performed as previously described (Nelson et al. 2004; Hayashi et al. 2007). Briefly, embryonic whole heads, P0-P7 half-heads (with brains removed), or P14-adult isolated vestibular and cochlear tissues were fixed overnight at $4^{\circ} \mathrm{C}$ in modified Carnoy's solution [60\% ethanol, $11.1 \%$ formaldehyde ( $30 \%$ of $37 \%$ stock), $10 \%$ glacial acetic acid], dehydrated though an EtOH series, prepared for paraffin embedding, and sectioned at 6 $8 \mu \mathrm{m}$. Slides were baked overnight at $68^{\circ} \mathrm{C}$, dewaxed in xylene, rinsed in $100 \% \mathrm{EtOH}$, and air-dried at room temperature. Overnight hybridization and subsequent washes were carried out at $68^{\circ} \mathrm{C}$. Hybridized probe was detected using anti-digoxygenin alkaline phosphatase conjugated antibody (1:2,000 dilution, Roche Biochemical, Indianapolis, IN, USA) and visualized with NBT/ BCIP for a blue precipitate. After in situ hybridization, sections were post-fixed in 4\% PFA, rinsed in PBS, and processed for fluorescent immunohistochemistry as described below.

\section{Antibodies}

For section and whole-mount immunohistochemistry, performed as described below, we used the following primary antibodies: chicken anti-GFP (1:500 dilution, Abcam, USA, cat. no. AB13970); goat anti-Jag1 (1:300, Santa Cruz Biotechnology, USA, Jag1 C-20, cat. no. SC-6011); goat anti-Sox2 (1:500, Santa Cruz Biotechnology, Sox2 Y-17, cat. no. SC-17320); rabbit antiProx1 (1:500, Chemicon, USA, cat. no. AB5475); rabbit anti-Calretinin (1:2,000, Swant, Switzerland); rabbit anti-actNotch1 (1:500, Cell Signaling Tech, cleaved Notch 1 Val1744); rabbit anti-Myosin6 (1:1,000 Proteus Biosciences, USA, cat. no. 25-6790); and rabbit anti-Calbindin (1:500, Millipore, USA, Calbindin D-28k, cat. no. AB1778).

\section{Activated Notch1 immunohistochemistry}

Immunolabeling for activated Notch1 was performed as described (Nelson et al. 2007). Briefly, P3 half-heads, with brains removed, were fixed overnight at $4^{\circ} \mathrm{C}$ in modified Carnoy's solution, dehydrated though an EtOH series, prepared for paraffin embedding, and sectioned at $6-8 \mu \mathrm{m}$. Slides were baked overnight at $68^{\circ} \mathrm{C}$, dewaxed in xylene, rinsed in $100 \% \mathrm{EtOH}$, and airdried at room temperature. Antigen retrieval was accomplished by autoclave treatment $\left(5 \mathrm{~min}, 105^{\circ} \mathrm{C}\right)$ in TE buffer (10 mM TrisCl, $1 \mathrm{mM}$ EDTA, pH 9.0). Sections were washed with PBS, blocked in $10 \%$ goat serum in phosphate buffer with Tween 20 (PBT) for $1 \mathrm{~h}$, incubated with rabbit anti-actNotch1 antibody overnight, washed four times with PBS, incubated with goat-anti rabbit alkaline phosphatase (1:500, Sigma) for $1 \mathrm{~h}$, washed four times with PBT, equilibrated with NTMT, pH 9.0, and incubated in NBT/BCIP substrate (Sigma). Sections were washed in PBS and subjected to sequential immunolabeling and fluorescent detection with primary and secondary antibodies as described below, followed by DAPI counterstaining and mounting.

\section{Fluorescent immunohistochemistry of frozen and paraffin sections}

Embryos were collected from timed pregnant Hes5-GFP mice and staged according to Kauffman (1992). For postnatal mice, P0 was defined as the day of birth. Embryonic whole heads or P0-P5 half-heads were fixed overnight in $4 \% \mathrm{PFA}$ in PBS at $4^{\circ} \mathrm{C}$. Adult cochlea were isolated from temporal bones, the stapes was removed from the oval window, a small opening was made in the apex, and cold 4\% PFA in PBS was perfused through the cochlea with a syringe. Perfused cochlea were then fixed overnight in $4 \% \mathrm{PFA}$ in $\mathrm{PBS}$ at $4^{\circ} \mathrm{C}$, washed $3 \times 30 \mathrm{~min}$ in PBS, and decalcified in $0.27 \mathrm{M}$ EDTA in PBS for $48 \mathrm{~h}$ at $4^{\circ} \mathrm{C}$. After fixation and decalcification (for adult cochlea), whole cochlea or heads were cryoprotected through graded sucrose in PBS (10\% sucrose, $15 \%$ sucrose, $15 \%$ sucrose with $50 \%$ OCT), then embedded in OCT (Tissue Tek), frozen in a bath of ethanol and dry ice, sectioned at $10 \mu \mathrm{m}$, and mounted on Superfrost+ slides (Fisher Scientific). Slides with cryosections (or paraffin sections already processed for act-Notch1 immunolabeling or in situ hybridization) were then washed briefly in PBS and blocked for $1 \mathrm{~h}$ in $10 \%$ fetal bovine serum (FBS) in PBS with $0.1 \%$ TritonX-100 at room temperature. Primary antibodies were diluted in block and incubated overnight at $4^{\circ} \mathrm{C}$. Slides were then washed in PBS $3 \times 10 \mathrm{~min}$ and incubated in speciesspecific fluorescent-labeled secondary antibodies AlexaFluor 488, 568, or 594 nm (1:500, Invitrogen). After immunostaining, slides were coverslipped in Fluoromount G (Southern Biotechnology, Birmingham, AL, USA). Images of most stained sections were acquired on a Zeiss Axioplan 2 microscope equipped with DIC optics and a Spot camera. Images of adult cochlear sections were also captured on a Zeiss LSM Pascal confocal microscope and processed using Improvision Volocity (3.0.2). Images were compiled with Adobe Photoshop 7.0. Within each figure, comparable imaging settings were used to capture all images of Hes5-GFP immunolabeling from sectioned tissues so that expression levels could be compared between ages and tissues.

\section{Whole-mount immunohistochemistry}

Adult inner ears were isolated from temporal bones, the stapes was removed from the oval window, a small opening was made in the apex, and cold 4\% PFA in PBS was perfused through the cochlea with a syringe. 
Perfused cochlea were then fixed overnight in $4 \%$ PFA in PBS at $4^{\circ} \mathrm{C}$, washed $3 \times 30 \mathrm{~min}$ in PBS, decalcified in $0.27 \mathrm{M}$ EDTA in PBS for $48 \mathrm{~h}$ at $4^{\circ} \mathrm{C}$, and washed in PBS $3 \times 30 \mathrm{~min}$. P3 cochlea were dissected from temporal bones and fixed in 4\% PFA in PBS for $3 \mathrm{~h}$ at $4^{\circ} \mathrm{C}$ then washed in PBS $2 \times 30 \mathrm{~min}$. P3 and decalcified adult inner ears were then dissected to isolate the cochlea and vestibular organs from the bony capsule. To expose the organ of Corti, the anlage of the vascularis and the tectorial membrane were removed using fine forceps. The vestibular organs were dissected to expose the epithelia and otoconia were removed from the utricle and saccule by directing a stream of PBS across the surface from a syringe with a $30-\mathrm{G}$ needle. Tissue was permeabilized in PBS $/ 0.1 \%$ TritonX-100 for $1 \mathrm{~h}$ and blocked for $2 \mathrm{~h}$ in $10 \%$ FBS in PBS with $0.1 \%$ TritonX-100 at room temperature. Primary antibodies were diluted in block and cochlear and vestibular tissues were incubated together overnight at $4^{\circ} \mathrm{C}$. Tissues were washed in block and incubated overnight at $4^{\circ} \mathrm{C}$ in species-specific fluorescent-labeled secondary antibodies: AlexaFluor 488 or $568 \mathrm{~nm}$ (1:500, Invitrogen). Tissues were washed in PBS and coverslipped in PBS/Glycerol. Confocal images of whole mounts were captured on a Zeiss LSM Pascal confocal microscope and 2-photon microscopic images were captured using an Olympus FV1000 MPE multiphotonmicroscope equipped with the 25X SuperObjective (Olympus) and Mai Tai laser (Spectra Physics). Images were processed using Improvision Volocity (3.0.2) and Adobe Photoshop (7.0). We were able to visualize the endogenous Hes5-GFP (without immunostaining) in live or fixed whole-mount cochlear tissue from P0-P8 mice and vestibular tissue from $\mathrm{P} 0$-adult mice using standard fluorescent microscopy. However, in cochlear tissue from embryonic mice or mice older than P8, we found the endogenous GFP to be too weak to image clearly, and it was sensitive to photo bleaching. Therefore, we used immunofluorescent labeling with antibodies against GFP to visualize and image the pattern of Hes5-GFP in the cochlea prior to P0 and after P8. In the adult vestibular sensory epithelia, the endogenous GFP was bright enough to image without immunostaining. However, to improve photostability and intensity for whole-mount confocal z-sectioning, we typically used immunolabeling against GFP in these tissues.

\section{RESULTS}

Hes5-GFP expression in the developing cochlea mimics the pattern of Hes 5 transcription

Hes 5 has been reported to be expressed in the embryonic cochlea; however, there is some debate over the specific spatial and temporal pattern of its expression (Lanford et al. 2000; Zheng et al. 2000;
Zine et al. 2001; Tang et al. 2006). Moreover, the expression pattern of Hes 5 in the postnatal and adult mammalian cochlea has not been investigated. We used Hes5-GFP transgenic mice and in situ hybridization to determine the expression pattern of Hes 5 in the embryonic and postnatal cochlea. In order to determine the spatial and temporal pattern of Hes 5 expression during embryonic and neonatal development, we performed in situ hybridization for Hes 5 in paraffin sections of mouse cochlear tissues from E12.5-P0. We compared the pattern of Hes 5 in situ hybridization signal with the pattern of Hes5-GFP expression in similar cochlear sections from age-matched Hes5-GFP mice (Fig. 1). At all ages, we found that the pattern of Hes5-GFP mimics the pattern of Hes 5 messenger RNA (mRNA) labeling via in situ hybridization with remarkable precision. Using both methods, we first detected Hes 5 in the developing auditory epithelium of the cochlea at E14.5 where it appears as a restricted band of cells in the medial floor of cochlear duct (A, A', B, and $\mathrm{B}^{\prime}$ in Fig. 1). Hes5-GFP immunolabeling was detectable at this age in the base and apex of the cochlear duct as well as in the spiral ganglia (A and A' in Fig. 1). In the auditory sensory epithelium at this age, the intensity of Hes5-GFP expression was stronger in the basal turns than in the most apical turn where it appeared faint and dispersed (A in Fig. 1). In situ hybridization signal for Hes 5 in the cochlea at this early time point was weak but clearly restricted to a similar narrow band of cells in the central floor of the cochlear duct in the basal turns and presumptive glial cells in the spiral ganglia (B, and B' in Fig. 1). In the apex of the cochlea, at this age, we were not able to discriminate signal from background using in situ hybridization for Hes5, presumably due to lower sensitivity of in situ hybridization compared to detection of Hes5-GFP (B and B' in Fig. 1). We did not detect Hes 5 expression in the nascent cochlear duct or spiral ganglia at E12.5 or E13.5 using in situ hybridization or Hes5-GFP, although we did find Hes5-GFP expression in the developing vestibular patches at both of these ages, consistent with earlier findings (data not shown; Shailam et al. 1999). At E17.5, developing inner and outer hair cells (arrows and arrowheads, respectively, in C and D in Fig. 1) and supporting cells have become specified and can be identified, based on their location and morphology, in transverse sections through the auditory epithelium. With in situ hybridization, we found that Hes 5 expression at this stage is restricted to a particular subset of cochlear supporting cells. Specifically, Hes 5 expression appears to be strong in the region of Dieters' and outer pillar cells, which lie underneath the outer hair cells, and less intense in the more medial supporting cells, which surround the inner hair cells and a population of cells in the greater epithelial ridge (GER; D in Fig. 1). Similarly, Hes5-GFP expression at E17.5 (C in Fig. 1) is 

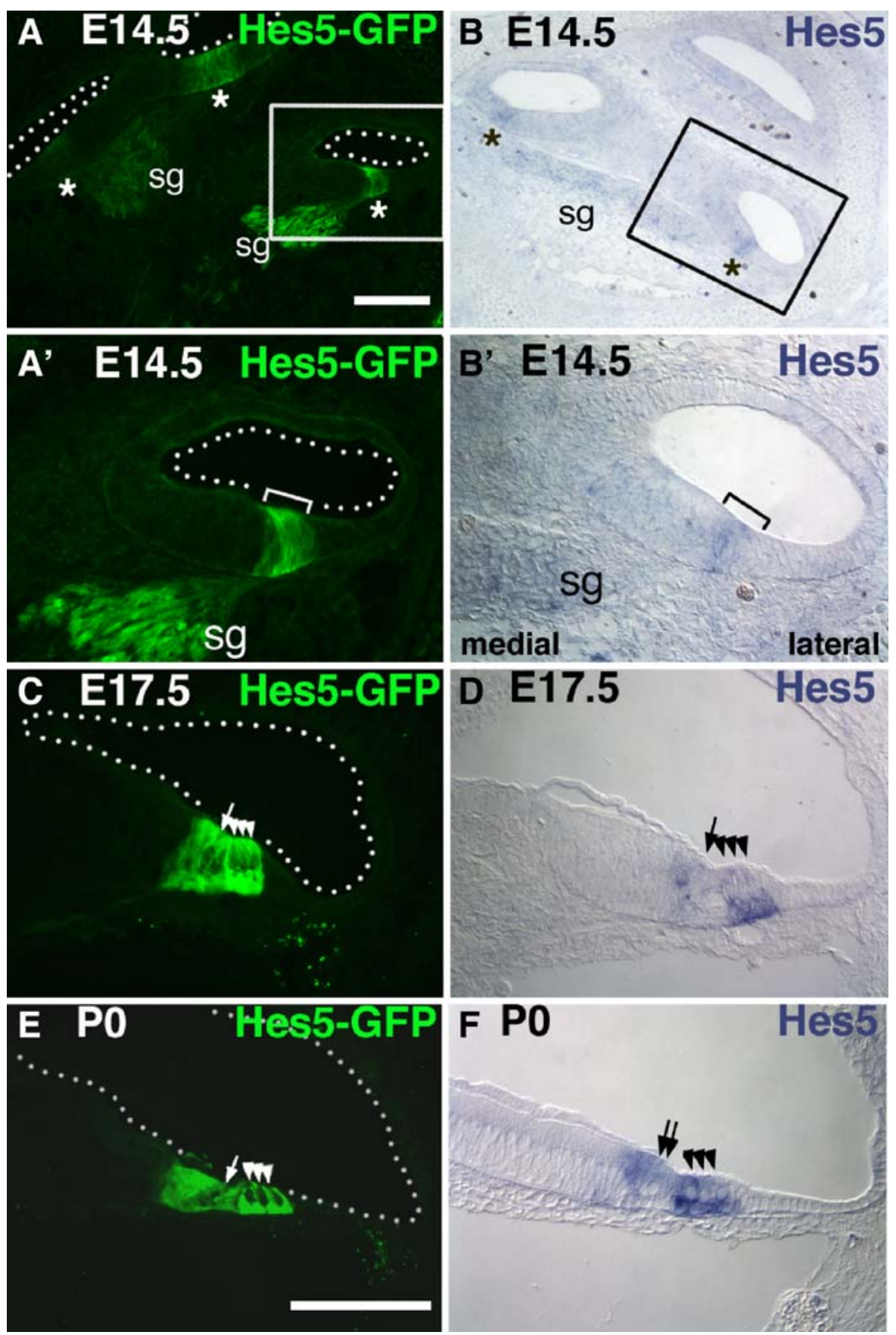

FIG. 1. Hes5-GFP mimics expression of Hes5 in supporting cells of the developing cochlea. Hes5-GFP expression in embryonic cochlear sections $\left(\mathbf{A}, \mathbf{A}^{\prime}, \mathbf{C}\right.$, and $\left.\mathbf{E}\right)$ compared to similar sections probed for expression of Hes5 with in situ hybridization (B, $\mathbf{B}^{\prime}, \mathbf{D}$, and $\left.\mathbf{F}\right)$. A Low magnification view of an E14.5 cochlea section shows that Hes5-GFP is expressed in three turns of the cochlea (asterisks) and in the spiral ganglion ( $\mathrm{sg}$ ). B Low magnification view of an E14.5 cochlea section probed for expression of Hes5 (blue) shows low level of signal in the two basal turns of the cochlea (asterisks) and the spiral ganglion (sg). $\mathbf{A}^{\prime}$ High magnification view of the boxed region in $\mathbf{A}$, mid-basal turn of the E14.5 cochlea, where Hes5-GFP labeling (bracket) is visible in a narrow band of cells in the floor of the cochlear duct. B' High magnification view of the boxed region in $\mathbf{B}$, mid-basal turn of the E14.5 cochlea. Hes5 in situ hybridization labeling (bracket) is low but

visible in a narrow band of cells in the floor of the cochlear duct, similar to Hes5-GFP (compare $\mathbf{A}^{\prime}$ to $\mathbf{B}^{\prime}$ ). $\mathbf{C}$ Section of E17.5 Hes5-GFP cochlea middle turn; expression is seen in supporting cells that surround inner hair cells (arrow) and outer hair cells (arrowheads) and in a small part of the GER. D E17.5 cochlear middle turn section probed for expression of Hes5; signal is localized to supporting cells in a similar pattern to Hes5-GFP at this age (compare $\mathbf{C}$ to $\mathbf{D}$ ). E P0 middle cochlear turn shows Hes5-GFP expression is strong in supporting cells that underlie and surround the outer hair cells and slightly weaker in more medial supporting cells and the GER. F P0 cochlea section probed for expression of Hes5 has a similar pattern to Hes5-GFP (E). Dotted lines in left panels outline the lumena of the cochlear duct. sg spiral ganglia. Scale bars in $\mathbf{A}$ and $\mathbf{E}=100 \mu \mathrm{m}$. Scale bar in $\mathbf{A}$ applies to $\mathbf{A}-\mathbf{B}$; scale bar in $\mathbf{E}$ applies to $\mathbf{A}^{\prime}-\mathbf{B}^{\prime}$ and $\mathbf{C}-\mathbf{F}$. 
strong in Dieters' and outer pillar cells. Lower intensity expression is seen in the supporting cells surrounding the inner hair cells, including the inner pillar cells, inner phalangeal cells, border cells, and a portion of the cells in the GER. At birth, the pattern of Hes 5 expression in the Hes5-GFP mouse and tissue probed with Hes5 (E and F, respectively, in Fig. 1) is similar to that seen at E17.5, strong in the four supporting cells that underlie the outer hair cells and less intense in the more medial supporting cells. The organ of Corti is more differentiated at this stage and individual cells can more easily be identified in these transverse sections, but the overall pattern of Hes 5 expression at birth is very similar to that at E17.5. The Hes5-GFP signal in the spiral ganglia appeared strongest at E14.5, where it could be seen in glia surrounding the spiral ganglion neuron cell bodies and weakly in glia tracking along the nerve fibers to the developing organ of Corti (A and A' in Fig. 1). By E17.5, the Hes5-GFP expression was notably reduced in the spiral ganglia compared to the organ of Corti, only faintly visible surrounding the spiral ganglion neuron cell bodies and undetectable in the fiber tracks (data not shown, C in Fig. 1.) Hes5-GFP could still be very faintly detected in glia surrounding the spiral ganglion neurons as late as P3 (data not shown), but was not seen at later ages.

Hes5-GFP is expressed in the developing organ of Corti at E14.5

We used Sox2 and Jag1 immunolabeling to further characterize the spatial pattern of Hes5-GFP in the E14.5 cochlea. At this time point in cochlear development, the prosensory region has been specified, and hair cell differentiation, marked by expression of Atoh1, is just beginning (Chen et al. 2002; Woods et al. 2004). Jagged1 (Jag1) encodes a Notch ligand known to be expressed in, and required for establishment of, the early prosensory domains of the inner ear during development and later becomes restricted to auditory and vestibular supporting cells (Lewis et al. 1998; Morrison et al. 1999; Zine et al. 2000; Kiernan et al. 2001; Tsai et al. 2001; Brooker et al. 2006; Oesterle et al. 2008). We labeled E14.5 Hes5-GFP cochlea cryosections with antibodies to Jag1 and GFP (A, B-B" in Fig. 2). We found that the region of Hes5-GFP expression, in the central floor of the cochlear duct, is adjacent to and partially overlapping with the Jag1 domain on the medial side (B-B" in Fig. 2). The region of Jag1 labeling appears most intense at its lateral edge, where it merges with the Hes5-GFP region. Similarly, the strongest Hes5GFP labeling can be seen at the medial side of the Hes5-GFP domain, adjacent to the Jag1 region.

Sox2 is a HMG-box transcription factor required for development of the inner ear sensory epithelia
(Kiernan et al. 2005b). Expression of Sox2 marks the early prosensory domain of the cochlea and is restricted to supporting cells during development and in the mature cochlea (Kiernan et al. 2005b; Hume et al. 2007; Dabdoub et al. 2008; Oesterle et al. 2008). At E14.5, Sox2 is expressed at high levels in the medial floor of the cochlear duct and a lower level in the region of the GER (C-C" in Fig. 2). The region of high Sox2 expression is overlapping with Hes5-GFP (C" in Fig. 2). Thus, Hes5 expression first occurs in the central floor of the cochlear duct at E14.5 within the prosensory domain from which the organ of Corti arises.

Hes5-GFP is restricted to a specific subset of cochlear supporting cells during development

Our initial analysis of Hes 5 expression with in situ hybridization and Hes5-GFP indicated that expression of this gene is restricted to a subset of supporting cells during late embryonic development ( $\mathrm{C}-\mathrm{F}$ in Fig. 1). We found that this pattern of Hes 5 expression in the organ of Corti is maintained in the neonatal cochlea. To further characterize the pattern of Hes 5 expression and understand the arrangement and cellular structure of the Hes5-positive supporting cell population, we performed immunolabeling and imaging analysis of Hes5-GFP cochlea at P3 (Fig. 3). Prox1 specifically marks the nuclei of the two rows of pillar cells and three rows of Dieters' cells in the developing and postnatal cochlea (B and B' in Fig. 3; BerminghamMcDonogh et al. 2006; Kirjavainen et al. 2008). We used Prox1 immunolabeling in whole-mount preparations of P3 Hes5-GFP cochlea to confirm the expression of Hes5-GFP in the Prox1-positive supporting cell population (A-C and $A^{\prime}-C^{\prime}$ in Fig. 3). In surface (XY plane, $A^{\prime}-C^{\prime}$ in Fig. 1) and transverse ( $\mathrm{ZY}$ plane, $\mathrm{A}-\mathrm{C}$ in Fig. 3) views of P3 cochlea taken from confocal zsectioned micrographs, all Prox1-positive supporting cells are labeled with Hes5-GFP. The Hes5-GFP fills the supporting cells, revealing the long extensions of the pillar cells and Dieters' cells that intercalate between the hair cells and span the depth of the epithelium (A, D, I-I' in Fig. 3).

We used similar preparations and imaging methods of whole-mount P3 cochlea labeled with anti-Calretinin to examine the spiral ganglion nerve endings and their spatial relationship with the Hes5-GFP-positive supporting cells (D-F and D'-F' in Fig. 3). Calretinin is a calcium-binding protein expressed in type I spiral ganglion cells and inner and outer hair cells in the neonatal cochlea (Dechesne et al. 1994; Sage et al. 2000; E-E' in Fig. 3). At P3, type I spiral ganglion neurons are in a stage of refinement and plasticity where they innervate both inner and outer types of hair cells (Pujol 1985; Echteler 1992; Simmons 1994; 

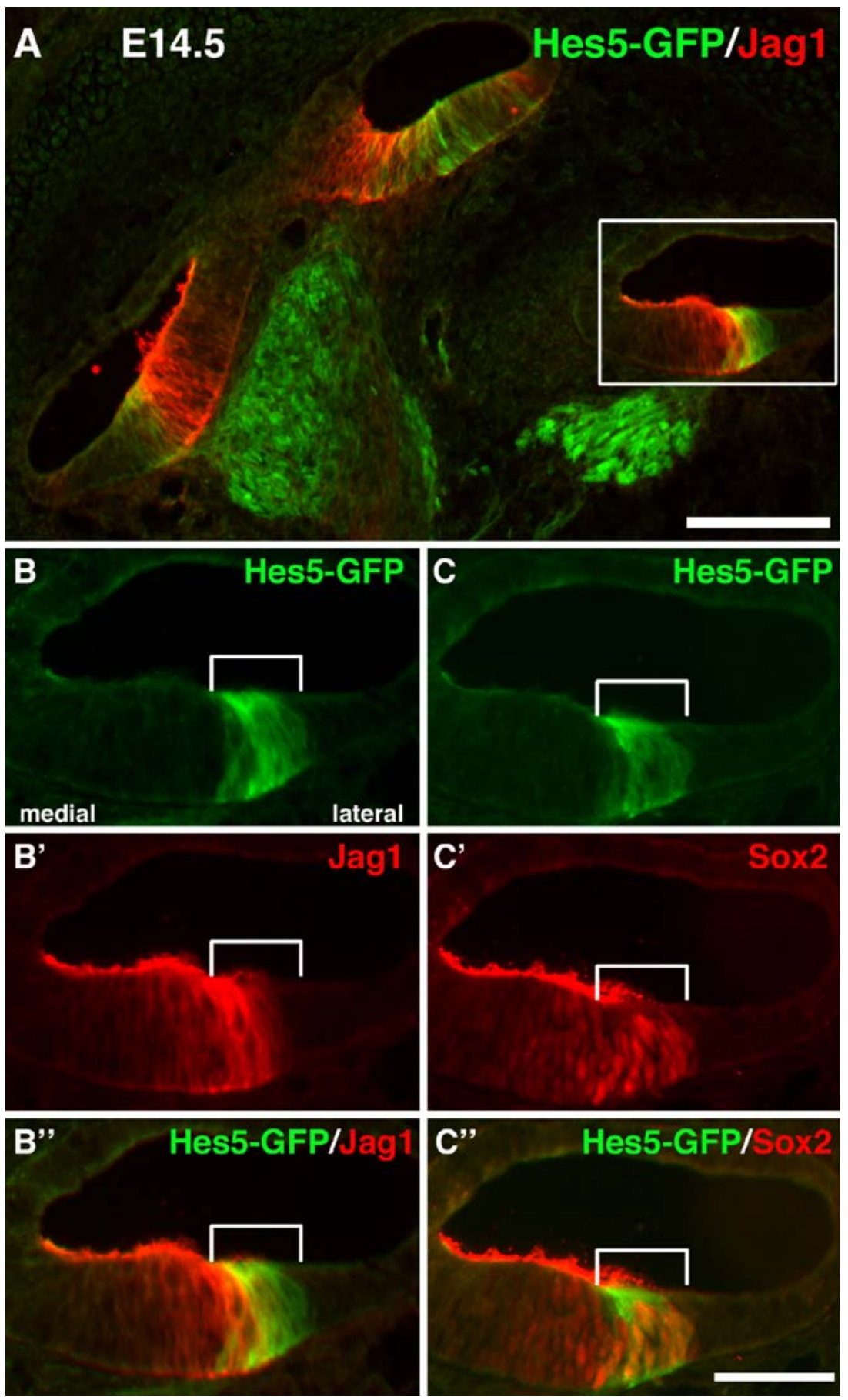

FIG. 2. Hes5-GFP overlaps partially with Jag1 expression and lies within the Sox2-labeled prosensory domain of the developing cochlea at E14.5. Sections of E14.5 Hes5-GFP cochlea were labeled with antibodies to GFP and Jag1 (A, B-B'") or Sox2 (C-C'"). A Low magnification view of three Hes5-GFP cochlear turns stained for Jag1 and GFP. B-B" High magnification views of boxed region in A,

mid-basal turn showing Hes5-GFP (brackets, B), Jag1 (B' $\left.{ }^{\prime}\right)$, and merged $\left(\mathbf{B}^{\prime \prime}\right)$. C-C" Similar mid-basal turn labeled with Hes5-GFP $(\mathbf{C})$, Sox2 $\left(\mathbf{C}^{\prime}\right)$, and merged $\left(\mathbf{C}^{\prime \prime}\right)$. Note that there is nonspecific labeling of the tectorial membrane in $\mathbf{B}-\mathbf{B}^{\prime \prime}$ and $\mathbf{C}-\mathbf{C}^{\prime \prime}$. Scale bar in $\mathbf{A}=100 \mu \mathrm{m}$. Scale bar in $\mathbf{C}^{\prime \prime}=50 \mu \mathrm{m}$ and applies to $\mathbf{B}-\mathbf{B}^{\prime \prime}$ and $\mathbf{C}-\mathbf{C}^{\prime \prime}$.

Huang et al. 2007). Consistent with these earlier studies, we found that anti-Calretinin-labeled spiral ganglion neurites in the P3 cochlea projected to the inner spiral plexus (isp, bracket E' in Fig. 3) region beneath the row of inner hair cells and extended

beyond this, as neurites projected to the $\mathrm{OHC}$ region and formed three rows of outer spiral bundles (arrowheads, E' in Fig. 3) beneath the OHCs (E-E' in Fig. 3). Earlier studies have shown that some neurite fibers in the organ of Corti are in close 


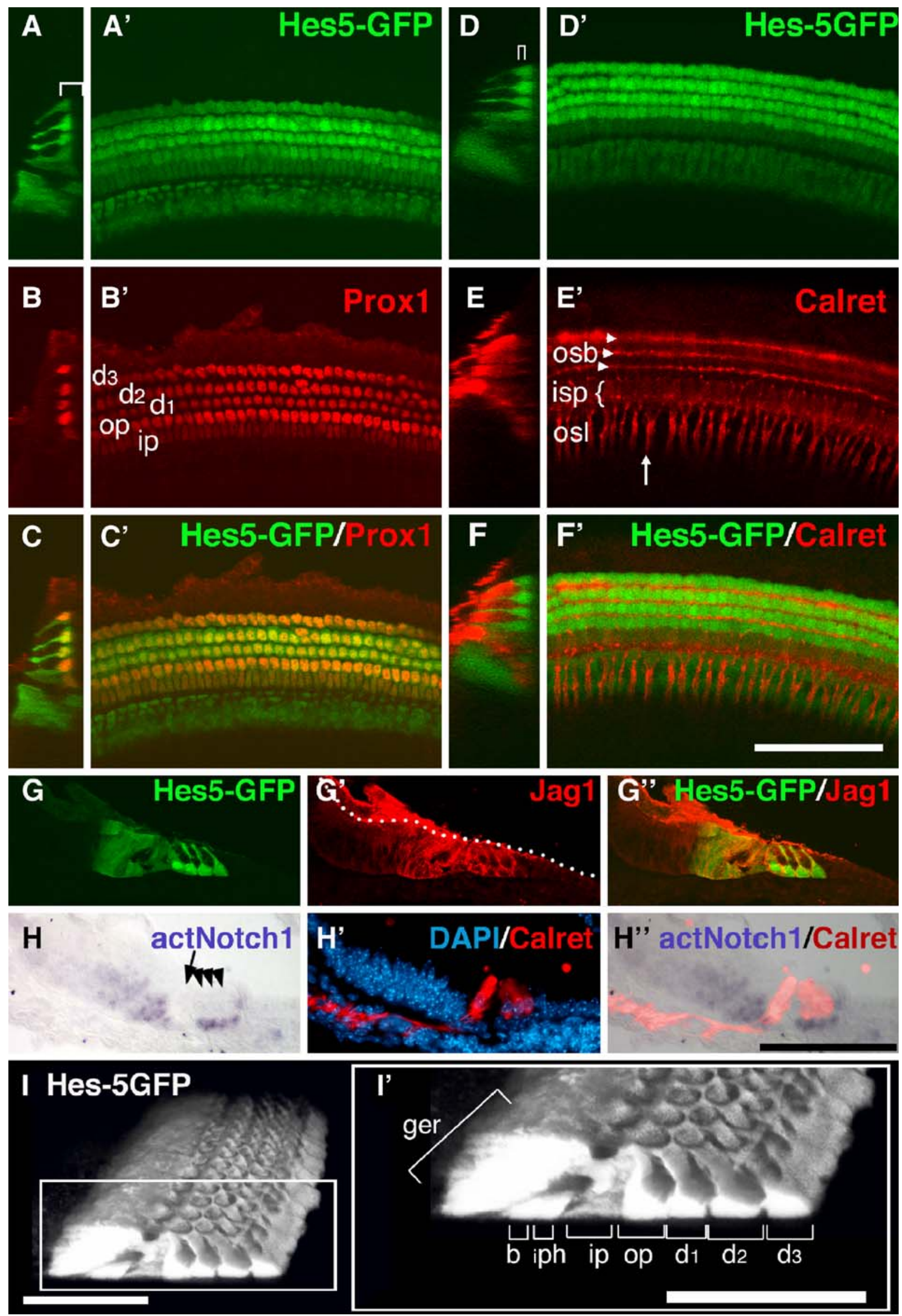


FIG. 3. Hes5-GFP is expressed in a specific population of cochlear supporting cells in a pattern similar to activated Notch1. P3 cochlear tissues from Hes5-GFP mice were processed for immunohistochemistry with antibodies against Prox1 $\left(\mathbf{A}-\mathbf{C}, \mathbf{A}^{\prime}-\mathbf{C}^{\prime}\right)$, Calretinin (D-F, $\mathbf{D}^{\prime}-$ $\left.\mathbf{F}^{\prime}\right)$, Jag1 and GFP $\left(\mathbf{G}-\mathbf{G}^{\prime \prime}\right)$, or activated-Notch1 and Calretinin $\left(\mathbf{H}-\mathbf{H}^{\prime \prime}\right)$, and patterns were compared to Hes5-GFP. A-C, $\mathbf{A}^{\prime}-\mathbf{C}^{\prime} \mathrm{ZY}$ plane section and $X Y$ projection views, respectively, of a confocal image through the epithelium of a P3 Hes5-GFP organ of Corti labeled with anti-Prox1. The $X Y$ projection $\left(\mathbf{A}^{\prime}-C\right)$ is of a subset of the total $z$ series that spans the basal supporting cell nuclei, marked by the bracket in $\mathbf{A}$. D-F, $\mathbf{D}^{\prime}-\mathbf{F}^{\prime} \mathrm{ZY}$ plane section and XY projection views, respectively, of a confocal image through the epithelium of a P3 Hes5-GFP organ of Corti labeled with anti-Calretinin. The XY projection $\left(\mathbf{D}^{\prime}-\mathbf{F}^{\prime}\right)$ is of a thin subset of the total $\mathrm{z}$ series in the region of neurite projections underlying the hair cells, marked by the bracket in D. Bundled cochlear nerve fibers (arrow points to one example) traverse through the osseous spiral lamina (osl) in close contact with Hes5-GFP-labeled GER cells. Calyceal nerve endings forming the inner spiral plexus (isp) overlay the Hes5-GFP-positive inner phalangeal cells; the three rows of outer spiral bundles (osb), which run longitudinally beneath the outer hair cells, track precisely between the four rows of outer pillar and Dieter's cells. G-G" Transverse cryosection through a P3 Hes5GFP cochlea immunolabeled for Jag1 and GFP. The dotted line outlines the lumenal surface; above is nonspecific staining of the tectorial membrane. $\mathbf{H}-\mathbf{H}^{\prime \prime}$ Transverse paraffin section through a P3 cochlea labeled with antibodies to activated Notch1 and Calretinin. Arrow and arrowheads denote inner hair cell and outer hair cells, respectively. I, I' 3D projection of a P3 Hes5-GFP cochlea rendered from a two photon excitation z-series micrograph. os/ osseous spiral lamina, isp inner spiral plexus, osb outer spiral bundles, GER greater epithelial ridge, $b$ border cell, iph inner phalangeal cell, ip inner pillar cell, op outer pillar cell, d1-d3 Dieters' cells. Scale bar in $\mathbf{F}^{\prime}=100 \mu \mathrm{m}$ and applies to $\mathbf{A}-\mathbf{F}$ and $\mathbf{A}^{\prime}-\mathbf{F}^{\prime}$. Scale bar in $\mathbf{H}^{\prime \prime}=100 \mu \mathrm{m}$ and applies to $\mathbf{G}-\mathbf{G}^{\prime \prime}$ and $\mathbf{H}-\mathbf{H}^{\prime \prime}$. Scale bars in $\mathbf{I}$ and $\mathbf{I}^{\prime}=50 \mu \mathrm{m}$.

contact with supporting cells (Burgess et al. 1997; Okamura et al. 2002; Jagger and Housley 2003; Huang et al. 2007). Consistent with this, we found that the neurite projections in the P3 cochlea are closely associated with the supporting cells labeled by Hes5GFP (D-F and D'-F' in Fig. 3). The cochlear nerve fibers projecting into the organ of Corti, through the osseous spiral lamina to the IHC region, run between clusters of Hes5-GFP-labeled GER and border cells. Similarly, the nerve endings within the isp (bracket, E' in Fig. 3), forming calyceal innervation to the IHCs, overlay the Hes5-GFP-positive inner phalangeal cells. Most strikingly, the three rows of outer spiral bundles, which run longitudinally beneath the outer hair cells, were found to track precisely between the four rows of more lateral supporting cells, the outer pillar and Dieter's cells (D-D', E-E', and F-F' in Fig. 3). Thus, Calretinin labeling here highlights the tracts made by spiral ganglion neurite projections in the neonatal organ of Corti which are closely associated with the Hes5-GFP-positive population of supporting cells.

We also labeled P3 Hes5-GFP cochlea cryosections with Jag1 to examine the relationship between these two Notch pathway components in the late stages of cochlear development $(\mathrm{G}-\mathrm{G}$ ” in Fig. 3). At this stage,
Jag1 labels the membranes of the cochlear supporting cells and a portion of the GER ( $G$ ' in Fig. 3). We found a remarkable degree of overlap in the Hes5GFP and Jag1-labeled supporting cell populations. Like Hes5-GFP, Jag1 labels the supporting cells that lie directly underneath the hair cells, including the Dieters', pillar, border, and inner phalangeal cells. At this age, neither Jag1 nor Hes 5 is expressed in the non-sensory epithelial cells lateral to the Dieters' cells, specifically the Hensen's and Claudius cells. The Jag1 labeling in the GER extends slightly more medially than the Hes5-GFP, but otherwise, the two populations appear to overlap at this age.

We used an antibody specific to the activated form of Notch1 to examine the spatial pattern of Notch1 signal activation at P3 $(\mathrm{H}-\mathrm{H}$ ” in Fig. 3). In paraffin sections of P3 cochleae, actNotch1 immunolabeling was visualized with alk-phos NBT/BCIP (blue stain); hair cells and nerve fibers were labeled with antiCalretinin and nuclei were stained with DAPI $(\mathrm{H}-\mathrm{H}$ " in Fig. 3). The pattern of activated Notch1 expression is also similar to that of Hes5-GFP at this age, appearing strong in more lateral supporting cells and slightly less intense in the GER (compare G and $\mathrm{H}$ in Fig. 3). An earlier study used this antibody to report the pattern of activated Notch1 in cochlear development and described a rapid downregulation during the first postnatal week, with only very weak expression at P3 (Murata et al. 2006). We found that the actNotch1 expression pattern was similar to the previous report, but in our hands was still detectable in supporting cells at P3. The differences between our observations could be due to slight differences in mouse strain background (we use the C57BL6, which is the background of the Hes5-GFP, while Murata et al. worked with CBA/N mice) or differences in our tissue preparation and staining methods. Thus, we find that the expression of activated Notch1 correlates with the pattern of Hes5-GFP and Hes5 in situ hybridization signal in the early postnatal period of cochlear development.

In order to resolve and identify the individual cells that make up the Hes5-GFP population in the developing cochlea, we imaged whole-mount preparations of $\mathrm{P} 3$ cochlea with high-resolution two-photon excitation microscopy. While similar imaging may have been accomplished with confocal microscopy, two-photon excitation microscopy allowed collection of large numbers $(\sim 80)$ of thin optical sections $(0.5 \mu \mathrm{m})$ with little photobleaching of the GFP. We generated and analyzed z-series images and 3D projections (I and I' in Fig. 3) of two-photon excitation micrographs and were able to readily discern the individual Hes5-GFP-labeled cells and identify them based on their positional arrangement and cellular morphology. An oblique view of a 3D 
projection of the P3 Hes5-GFP cochlea shows the orderly arrangement and cellular shape of the supporting cells, their lumenal projections ensheathing hair cells, which appear as empty spaces in the epithelium (I in Fig. 3). Close examination of the transverse optical section that appears on the front edge of the projection shows the profiles of individual supporting cells arranged in their respective rows (I' in Fig. 3). The Hes5-GFP-labeled supporting cells include a cluster of cells in the GER, the border cells and inner phalangeal cells (which underlie and surround the inner hair cell), the inner and outer pillar cells, and three rows of Dieters' cells (labeled GER, b, iph, ip, op, d1, d2, and d3, respectively, in I' in Fig. 3). In general, we found that the level of Hes5-GFP expression in the P3 cochlea appears more intense in the Dieters' cells and outer pillar cells than in the supporting cells on the medial side of the organ of Corti (see A, A', D, D', and G in Fig. 3). However, the relative GFP intensity levels of the individual cells are not apparent in the 3D projection (I and I' in Fig. 3) because of the contrast and density settings required for rendering. This pattern is present throughout late embryonic and neonatal development and suggests that the more lateral supporting cells have comparatively higher levels of Notch1-Hes5 signaling than the supporting cells on the medial side of the organ of Corti and in the GER. In contrast to earlier in situ hybridization studies (Zheng et al. 2000; Zine et al. 2001), we did not detect Hes5 expression in the more lateral supporting cells of the lesser epithelial ridge, i.e., the Hensen's and Claudius cells, at any time during cochlear development.

\section{Hes 5 expression persists in the cochlea}

through the first postnatal week, after which it is rapidly downregulated

In order to determine the pattern of Hes 5 expression in the inner ear during postnatal development, we again turned to a combination of in situ hybridization and Hes5-GFP. We performed in situ hybridization for Hes 5 on inner ear tissues from mice collected at P3, P5, P7, P14, and adult ages. We found that in the early postnatal period of P3, Hes 5 mRNA expression was still detectable in a similar pattern to that of $\mathrm{P} 0$ throughout the organ of Corti, but was only faintly expressed in the basal turn (data not shown). At P5, Hes 5 mRNA was still detectable in the apex in a similar pattern to earlier ages (A in Fig. 4), but in the basal region was nearly imperceptible (C in Fig. 4). We found that Hes 5 mRNA is not expressed in the auditory epithelium at P7 (data not shown) or P14 ( $\mathrm{F}$ in Fig. 4). Thus, our Hes 5 mRNA expression analysis of the postnatal cochlea indicates that expression of this gene is downregulated rapidly in a base to apex sweep that begins shortly after birth and is concluded around P7.

We next analyzed the pattern of Hes5-GFP expression in the postnatal cochlea to see how it correlated with our in situ hybridization study. In the P7 cochlea, Hes5-GFP is expressed in the apex in a similar pattern to that observed at earlier ages, appearing in the Dieters' and outer pillar cells, and at a lower level in the more medial supporting cells and the GER (B in Fig. 4). In the base of the P7 cochlea, we found that Hes5-GFP is quite faint, detectable only dimly in the supporting cells (D in Fig. 4). We were still able to visualize endogenous Hes5-GFP in the apex of whole mount cochlea preparations as late as P8 and used confocal z-series microscopy to generate 3D projections of the pattern in the apex at this age ( $\mathrm{E}$ in Fig. 4). Undetectable in the base at P8, Hes5-GFP was restricted to the extreme apex at this age and was notably dim compared to similar whole-mount preparations at P3 (see Fig. 3), requiring higher laser power and detector gain for visualization with confocal microscopy. Due to the low levels of Hes5-GFP in the supporting cells at this age, compared to P3, the cellular resolution in images is reduced and cells appear less dense (compare A, D, and I in Fig. 3 and E in with Fig. 4). Hes5-GFP was completely undetectable in the auditory sensory epithelium of tissues examined at P12 (not shown), P16 (G in Fig. 4), and adult ages (A and A' in Fig. 6). Thus, we found that Hes5GFP expression in the cochlea is downregulated in a base to apex gradient beginning with reduced expression in the base around $\mathrm{P} 7$ and loss of expression in the apex between P8 and P12. This result is consistent with the findings of our Hes 5 in situ hybridization analysis where we saw a similar basal to apical downregulation of Hes 5 mRNA during the first postnatal week, though the loss of GFP is delayed relative to the in situ expression.

\section{Hes 5 is expressed in vestibular supporting cells throughout development and in adults}

We found that Hes 5 mRNA and Hes5-GFP are expressed in developing vestibular patches as early as E12.5 (data not shown) and in vestibular supporting cells at E17.5 (J and J' in Fig. 4). The Hes5-GFP pattern in the developing utricle and cristae includes expression in nearly all of the supporting cells of these organs, which can be seen surrounding nearly every hair cell of the utricle and horizontal crista in sections at E17.5 (J and J' in Fig. 4). We also found Hes5-GFP expression in the developing saccule where it was typically restricted to the peripheral edges and appeared less intense than the utricle or cristae ( $\mathrm{J}$ and J' in Fig. 4, asterisk). 


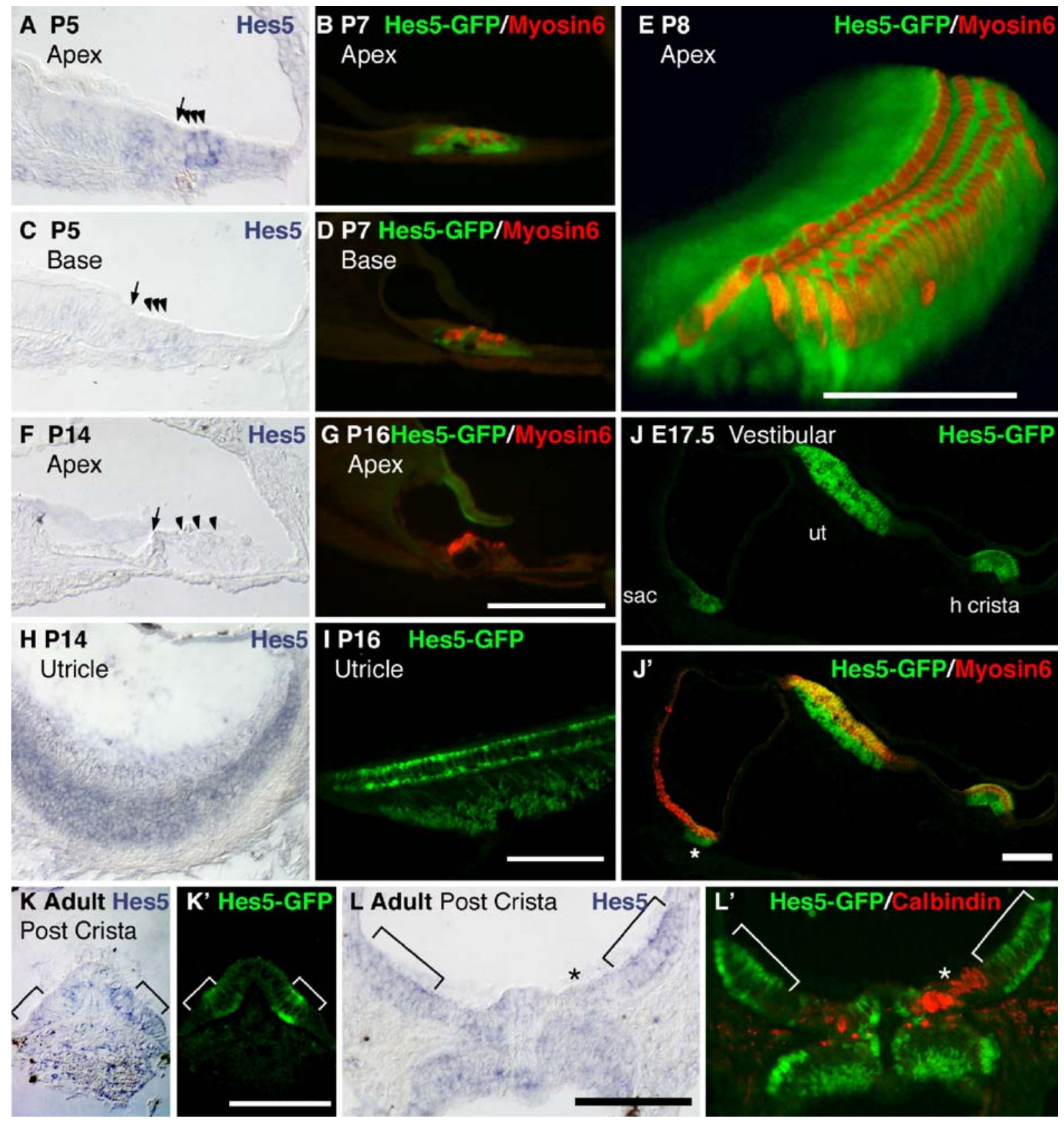

FIG. 4. Hes5 is downregulated in the neonatal cochlea but is expressed in mature vestibular supporting cells. Postnatal and juvenile cochlear sections were probed for Hes5 (A, C, F) and compared to similar sections of Hes5-GFP cochlea immunolabeled for GFP and the hair cell marker Myosin6 (B, D, G). Hes5 is expressed in cochlear supporting cells in the apex at P5 (A), but is nearly undetectable in the base at this age $(\mathbf{C})$ and is not detectable at P7 (not shown) or P14 (F). B, D, G Hes5-GFP is similarly downregulated in cochlear supporting cells such that it is present in the apex at P7 (B), but only weakly expressed in the base at P7 (D) and is not detectable at P16 (G). Hes5-GFP could still be detected in the apex as late a P8 and was bright enough to be visualized with confocal z-series microscopy to generate a $3 \mathrm{D}$ projection, immunolabeled with anti-Myosin6 (E). Although Hes5 was not detectable in the juvenile cochlea, it was clearly expressed in supporting cells of the P14 utricle, shown here in an oblique section $(\mathbf{H})$. Similarly, Hes5-GFP was expressed in supporting cells of the P16 utricle (I). J-J'
Cryosection through an E17.5 Hes5-GFP inner ear immunolabeled with antibodies to GFP (J) and Myosin6 (merged, $\mathbf{J}^{\prime}$ ). Hes5-GFP is expressed in supporting cells throughout the utricle and horizontal crista and in a subset of supporting cells in the periphery of the saccule (asterisk, $\mathbf{J}^{\prime}$ ). Adult Hes5-GFP vestibular tissues were probed for Hes5 and then immunolabeled for GFP (K-K' $\mathbf{K}^{\prime}$ and $\left.\mathbf{L}-\mathbf{L}^{\prime}\right)$ to confirm that the transgene expression mimics expression of Hes5. $\mathbf{K}^{-\mathbf{K}^{\prime}}$ Transverse section of an adult posterior crista shows Hes5 in situ hybridization signal $(\mathbf{K})$ and Hes5-GFP $\left(\mathbf{K}^{\prime}\right)$ are co-localized in the peripheral supporting cells (brackets). L-L' Oblique section through an adult posterior crista shows similar overlap between Hes5 in situ signal and Hes5-GFP (brackets, $\mathbf{L}$ and $\mathbf{L}^{\prime}$, respectively), but neither are overlapping with the central zone (type I) hair cell calyx marker Calbindin (asterisk, $\mathbf{L}^{\prime}$ ). Scale bar in $\mathbf{G}=100 \mu \mathrm{m}$ and applies to $\mathbf{A}-\mathbf{D}$ and $\mathbf{F}-\mathbf{G}$. Scale bar in $\mathbf{E}=100 \mu \mathrm{m}$. Scale bar in $\mathbf{I}=100 \mu \mathrm{m}$ and applies to $\mathbf{H}$ and $\mathbf{I}$. Scale bar in $\mathbf{J}^{\prime}=100 \mu \mathrm{m}$ and applies to $\mathbf{J}$ and $\mathbf{J}^{\prime}$. Scale bar in $\mathbf{K}^{\prime}=50 \mu \mathrm{m}$ and scale bar in $\mathbf{L}=100 \mu \mathrm{m}$. 
To determine the expression pattern of Hes 5 during postnatal development and in adults, we collected cristae and utricles from Hes5-GFP animals at P14 and adult ages and processed them for Hes 5 in situ hybridization. We found that Hes 5 mRNA was detectable in vestibular organs at P14 and adult ages ( $\mathrm{H}, \mathrm{K}$, and $\mathrm{L}$ in Fig. 4). In oblique sections through the P14 utricle, Hes 5 expression was visible in supporting cells in a honeycomb pattern surrounding Hes5negative hair cells (H in Fig. 4). Similarly, Hes5-GFP was expressed in supporting cells throughout the P16 utricle, which are seen to span the depth of the epithelium in transverse sections (I in Fig. 4). We also detected Hes 5 expression in adult cristae, visible in the peripheral supporting cells in transverse and oblique sections ( $\mathrm{K}$ and $\mathrm{L}$, respectively, in Fig. 4, brackets). We were able to visualize Hes5 mRNA and Hes5-GFP in the same sections by immunostaining for GFP after in situ hybridization (K, K', L, and L' in Fig. 4). We confirmed the co-localization of the Hes5-GFP with Hes 5 expression in the adult cristae where in transverse sections, it was highest in supporting cells in the peripheral margins and low or absent from the apices ( $\mathrm{K}$ and $\mathrm{K}$ ' in Fig. 4). Similarly, in oblique sections of the adult posterior crista, Hes5-GFP co-localized with Hes 5 expression in peripheral supporting cells and was low or absent in the apices, marked by antiCalbindin labeling ( $\mathrm{L}$ and L' in Fig. 4).

We further examined the Hes5-GFP expression pattern in whole-mount preparations of adult vestibular organs (Fig. 5). In surface views of adult utricles, Hes5GFP is expressed in supporting cells in a mosaic pattern throughout the epithelium (A and B in Fig. 5). We consistently observed highest levels of Hes5-GFP in the medial posterior region of the adult utricle where most supporting cells are labeled with the transgene. Within the striolar region of the utricle, labeled by Calbindin, Hes5-GFP expression was markedly reduced (B-B" and enlarged in $\mathrm{C}$ and $\mathrm{C}^{\prime}$ ). In a $3 \mathrm{D}$ projection of the region at the posterior tip of the striola (upper box in $\mathrm{B}$ " in Fig. 5), the Hes5-GFP-labeled supporting cells can be seen adjacent to the Calbindin-labeled striolar calyces (D in Fig. 5). The Hes5-GFP supporting cells in the adult utricle have a radial morphology which spans the depth of the sensory epithelium (D in Fig. 5). We never saw co-expression of Hes5-GFP in anti-Myosin6 or anti-Calbindin-labeled hair cells. Although we also found that Hes5-GFP is expressed in the adult saccule, Hes5-GFP expression in this organ was primarily restricted to a few scattered cells in the peripheral edges of the epithelium and appeared quite faint compared to the robust levels observed in the cristae and utricle.

In adult whole-mount preparations of the cristae of the semicircular canals, Hes5-GFP is expressed in supporting cells surrounding the peripheral margins of the epithelia ( $\mathrm{E}$ and $\mathrm{F}$ in Fig. 5). Hes5-GFP expression is strong in discrete bands of supporting cells along the lateral edges, but is absent from the central apices of the three cristae (E-E" in Fig. 5). In reptiles, birds, and some mammals, the anterior and posterior (vertical) cristae, but not the horizontal crista, are divided by a non-sensory structure whose function is unknown, called the eminentia cruciatum (for review, see Lysakowski and Goldberg 2004). Interestingly, the regions of Hes5-GFP expression in the anterior and posterior cristae extend over the apices of the epithelia adjacent to either side of the eminentia, essentially forming a border around the periphery of each half of the crista (F-F" in Fig. 5). This suggests that the eminentia does not merely bisect a single concentric structure but that it divides each vertical crista into two hemicristae, similar to those in birds and reptiles. The expression of Hes 5 specifically in the peripheral supporting cells of the cristae suggests that these supporting cells may be intrinsically different from supporting cells in the apices.

\section{Hes 5 is not expressed in the adult cochlea} after hair cell damage

Our findings that Hes5 is not expressed in the adult cochlea under normal conditions are consistent with the terminally differentiated status of adult cochlear supporting cells. Auditory hair cell regeneration from supporting cells in lower vertebrates appears to require their upregulation of Notch signaling (Stone and Rubel 1999; Ma et al. 2008). In order to determine whether the supporting cells of the mammalian cochlea respond to hair cell damage by a similar upregulation in Notch signaling, we analyzed the Hes5-GFP mice after hair cell damage. We induced hair cell damage by a single high-dosage injection of kanamycin followed by a single injection of the loop diuretic furosemide (Oesterle et al. 2008). We killed injected animals and uninjected littermate controls at 2 days $(n=3)$ and 4 days $(n=5)$ after treatment. OHCs were lost throughout most of the cochlea of injected animals, but inner hair cells were largely intact (Fig. 6). Hes5-GFP was not expressed in any of the normal adult cochlea (A and A' in Fig. 6 and merged with anti-Myosin6 in A" and A" in Fig. 6); we also did not find any expression in the cochlea after ototoxic drug injections (B-B"' in Fig. 6). To ensure detection of low levels of Hes5-GFP, we performed immunolabeling for GFP on adult tissues. We processed and analyzed damaged and control cochlear tissues together and included vestibular organs from the same animals as positive control tissues for Hes5-GFP immunolabeling. A comparison of Hes5-GFP expression in the positive control utricle tissue, processed and imaged alongside the cochlear tissues in $\mathrm{A}-\mathrm{A}$ "' and $\mathrm{B}-\mathrm{B}$ "' in Figure 6, is shown in $\mathrm{C}-\mathrm{C}$ "' in Figure 6. 
In frozen transverse sections of control and damaged Hes5-GFP cochlea (D and E, respectively, in Fig. 6), Hes5-GFP expression is also absent, while strong expression can be seen in a P3 frozen section stained and imaged alongside the adult specimens ( $\mathrm{F}$ in Fig. 6). Sox2 antibody labels the supporting cell nuclei in the same control and damaged adult sections (D' and E' in Fig. 6) and, as reported by Oesterle et al., is unchanged in the damaged cochlea (E' in Fig. 6). Thus, although supporting cells are still present in the damaged cochlea and express Sox2, they do not upregulate Hes5-GFP in response to hair cell death.

\section{DISCUSSION}

Hes5-GFP reports Notch signal activity in the inner ear

The reporter construct used to generate the Hes5GFP mice used in this study contains a 3-kb portion of the Hes 5 gene, including $1.6 \mathrm{~kb}$ of the $5^{\prime}$ flanking region, with eGFP cloned into the endogenous translational start site (Basak and Taylor 2007). The expression pattern of GFP in this transgenic line has been well characterized in the developing central nervous system where it is expressed in neural progenitors and correlates strongly with self-renewal capacity and multipotency (Basak and Taylor 2007). Hes5-GFP was found to be inducible by Notch1, and expression was nearly completely absent from Notch1deficient embryos (Basak and Taylor 2007). Among the four Notch receptors, only Notch1 has been conclusively shown to be expressed in the developing mammalian cochlea (Lewis et al. 1998; Shailam et al. 1999; Zine et al. 2000; Murata et al. 2006), although Notch3 was reported to be expressed in the early rat otocyst prior to cochlear differentiation (Lindsell et al. 1996). Hes5-GFP expression strongly correlates with expression of activated Notch1 in the developing inner ear such that they appear to be nearly identical spatial and temporal patterns (Fig. 3; Murata et al. 2006). Thus, Hes5-GFP appears to be a reliable readout of Notch signal activity in the inner ear.

\section{Hes 5 in embryonic development of the organ of Corti}

In this study, we have used a combination of approaches to define the pattern of expression of Hes 5 in the developing and mature inner ear. In the organ of Corti, we show that Hes 5 is expressed at a low level in the E14.5 cochlea approximately 12-24 h earlier than previously reported. Hes 5 expression at E14.5 appears in a discrete region in the central floor of the cochlear duct, which is largely overlapping with Jag1 and Sox2. Earlier studies from our lab and others have reported that nascent hair cells express the Notch ligand-encoding genes Dll1 and Jag2 beginning at E14.5, and Dll3 is expressed in hair cells about $24 \mathrm{~h}$ later (Lanford et al. 1999; Morrison et al. 1999; Zhang et al. 2000; Kiernan et al. 2005a; Hartman et al. 2007). Expression of these hair-cell-specific Notch ligands has been shown to be restricted to the developing hair cells, which appear at this stage as a single row of presumptive inner hair cells on the medial edge of the prosensory domain. Thus, the pattern of Hes 5 expression at E14.5 is slightly broader than that which might be expected to result from Notch signaling initiated by hair-cell-specific ligands alone. Since Jag1 protein is expressed throughout most of the Hes5positive region and the most intense region of Jag1 labeling is adjacent to the brightest Hes5-GFP cells, it is possible that Jag1-Notch signaling contributes to the expression of Hes 5 at E14.5. Further studies, such as examination of Hes5-GFP expression in Jag2/Dll1 mutants, would be necessary to determine how specific ligands contribute to Hes 5 signaling.

Notch signaling has been shown by several recent studies be active during, and essential for, specification of the prosensory domains, which is thought to occur in the mouse inner ear around E12.5 (Daudet and Lewis 2005; Brooker et al. 2006; Kiernan et al. 2006; Murata et al. 2006; Daudet et al. 2007; Hayashi et al. 2008). Since we confirmed that Hes5 is not expressed at this early stage and earlier studies showed that Hes5 ablation does not inhibit sensory patch formation (Zine et al. 2001), it is unlikely that Hes 5 participates in the process of sensory specification. Other Hes family transcription factors, HesR1 and HesR2, are expressed during the prosensory specification phase of early cochlear development and are more likely to be involved in this process (Hayashi et al. 2008). Thus, the expression of Hes5 in the prosensory region at E14.5 may represent a baseline of low-level Notch-Hes5 signaling that is set up with contributions from Jag1 just prior to initiation of lateral inhibition by hair-cell-specific Notch ligands.

The expression of Hes5-GFP in the glia of the spiral ganglia during early embryonic development (A, A', $\mathrm{B}$, and $\mathrm{B}^{\prime}$ in Fig. 1) suggests that the developing neurons express a Notch ligand which activates Notch signaling in the developing glia. This is consistent with known roles for Notch signaling in glial development and differentiation throughout the nervous system (Gaiano et al. 2000; Hojo et al. 2000; Morrison et al. 2000; Tanigaki et al. 2001; Ge et al. 2002; Taylor et al. 2007).

The expression pattern of Hes 5 during the middle and late stages of cochlear development, from E17.5 through the neonatal period, is consistent with a role for this gene in lateral inhibition. In this model, Notch signaling is activated in nascent supporting 


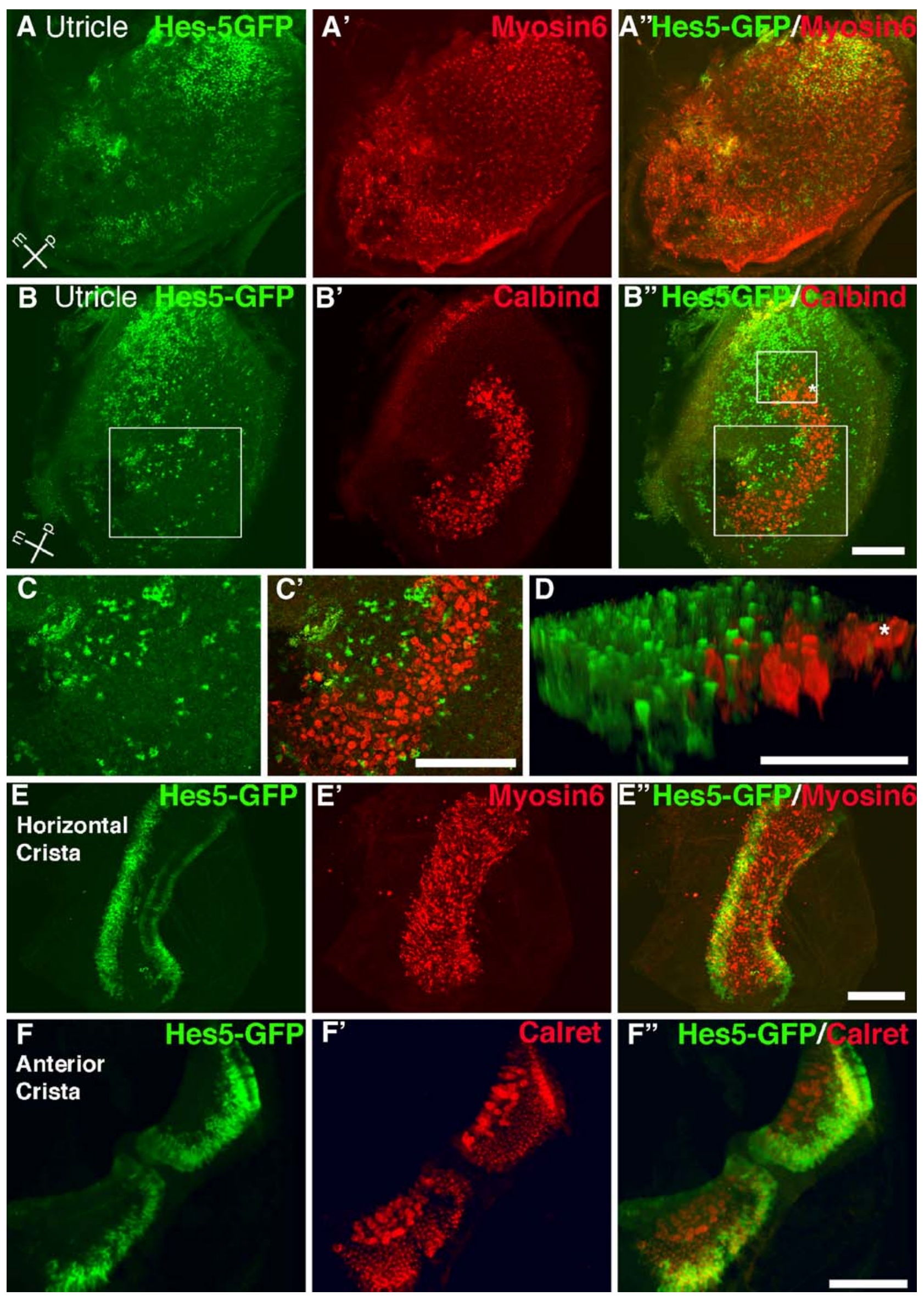


1FIG. 5. Hes5-GFP is expressed in a subset of adult vestibular supporting cells. Adult Hes5-GFP vestibular organs were immunolabeled for GFP and the hair cell marker Myosin6 (A-A" and $\left.\mathbf{E}, \mathbf{E}^{\prime \prime}\right)$, or the striolar (type I) hair cell calyx marker Calbindin (B-B', $\mathbf{C}-\mathbf{C}^{\prime}$, and D), or Calretinin $\left(\mathbf{F}-\mathbf{F}^{\prime \prime}\right)$ which labels both hair cells and type I hair cell calyxes. Images are brightest point projections (A-A", B-B', $\mathbf{C}-\mathbf{C}^{\prime}$, and $\mathbf{E}-\mathbf{E}^{\prime \prime}$ ) or 3D projections ( $\mathbf{D}$ and $\mathbf{F}-\mathbf{F}^{\prime \prime}$ ) of confocal z-series micrographs. Hes5-GFP is expressed in a mosaic pattern in the adult utricle; there is an area of high expression in the medio-posterior region of the macula and scattered cells throughout the epithelium (A, B). Only a few Hes5GFP labeled cells are found within the striolar region, labeled with anti-Calbindin (B-B"). The large boxed regions in $\mathbf{B}$ and $\mathbf{B}^{\prime \prime}$ are shown at higher magnification in $\mathbf{C}$ and $\mathbf{C}^{\prime}$, respectively. The smaller boxed region in $\mathbf{B}^{\prime \prime}$ is shown as an oblique $3 \mathrm{D}$ projection in $\mathbf{D}$, rotated slightly counterclockwise; the radial profiles of Hes5-GFP labeled supporting cells can be seen at the margins of the striolar region, marked by the Calbindin-labeled striolar calyxes (asterisk). E-E" A horizontal crista shows Hes5-GFP labeling in supporting cells of the peripheral margins. F-F" The anterior crista has Hes5-GFP labeling surrounding the periphery of each half of the organ in a concentric pattern. Scale bar in $\mathbf{B}^{\prime \prime}=100 \mu \mathrm{m}$ and applies to $\mathbf{A}-\mathbf{A}^{\prime \prime}$ and $\mathbf{B}-\mathbf{B}^{\prime \prime}$. Scale bars in $\mathbf{C}^{\prime}, \mathbf{E}^{\prime \prime}$, and $\mathbf{F}^{\prime \prime}=100 \mu \mathrm{m}$. Scale bar in $\mathbf{D}=50 \mu \mathrm{m}$.

cells by ligands presented on the surface of hair cells. Consistent with this, Hes 5 expression levels during cellular differentiation of the cochlea appear to be highest in the supporting cells in direct contact with hair cells. This is particularly evident by the high levels of Hes 5 present in the more lateral supporting cells, the Dieters' and outer pillar cells, which are each in contact with multiple outer hair cells (Fig. 3). Similarly, Hes 5 null mice produce extra cochlear hair cells that appear in three specific patterns: a row of additional outer hair cells along the lateral edge, occasional extra inner hair cells, and some ectopic hair cells in the GER (Zine et al. 2001). These extra hair cells likely arise from the same population of supporting cells that are labeled with Hes5-GFP during embryonic development. Additionally, Hes 5 appears to function in parallel with Hes 1 and HesR2 (Hey2), which are expressed in partially overlapping regions with $H e s 5$, and combination of mutations in either of these genes with loss of Hes 5 increases the overproduction of hair cells (Zine et al. 2001; Li et al. 2008).

Our description here substantially improves on earlier in situ hybridization studies that reported Hes 5 expression in the embryonic cochlea (Shailam et al. 1999; Lanford et al. 2000; Zheng et al. 2000; Zine et al. 2001; Tang et al. 2006; Li et al. 2008). While several of these studies accurately showed Hes 5 expression in the region of the Dieter's cells, most did not pick up the expression in other supporting cells or the GER and none provided single-cell resolution of the Hes5-positive population. Some of the earlier studies also reported Hes 5 expression in the more lateral supporting cells of the lesser epithelial ridge, i.e., the Hensen's and Claudius cells
(Zheng et al. 2000; Zine et al. 2001), where we did not detect Hes 5 expression at any time during cochlear development.

\section{Hes 5 in the neonatal cochlea correlates with supporting cell plasticity}

Hes 5 downregulation in the cochlea during the first postnatal week (Fig. 4) correlates with a similar loss of expression of Notch ligands in hair cells. Earlier, we reported that Dll1 and Dll3 are downregulated from base-to-apex in neonatal hair cells between P0 and P3, and expression of these two Notch ligands is lost from hair cells by P5 (Hartman et al. 2007). Thus, the spatial and temporal pattern of loss of Hes 5 expression in supporting cells closely follows the downregulation of Notch ligands in hair cells. The expression pattern of Notch ligands thus offers further support that Hes 5 expression is a result of Notch signaling initiated by ligands presented on the surface of hair cells. However, it is also possible that Jag1, expressed in supporting cell membranes, contributes to Hes 5 signaling during embryonic and postnatal development, particularly in the GER where Hes 5 is expressed in cells that do not appear to contact hair cells.

Another possible source of Notch ligands that could contribute to the Hes 5 signal in the organ of Corti are the spiral ganglion neurons. The expression of Hes5-GFP in the glia of the spiral ganglia during embryonic and neonatal development suggests that spiral ganglion neurons express Notch ligands. Additionally, we found that the spiral ganglion nerve endings are in close contact with Hes5-GFP-positive supporting cells in the neonatal cochlea (D-F' in Fig. 3). Although expression of Notch ligands in auditory nerve fibers has not been reported, Delta has been shown to be trafficked to neurites of other neurons, such as Drosophila ventral nerve cord neurons (Cornbrooks et al. 2007). Notch signaling has also been shown to be involved in regulating contactdependent neurite growth in mammalian neuronal cultures (Franklin et al. 1999; Sestan et al. 1999), suggesting that Delta-Notch signaling occurs in some neurites. Additionally, spiral ganglion neurons undergo a period of neurite retraction and pruning between P3 and P6 (Huang et al. 2007), which we found correlates spatially and temporally with loss of Hes 5 in the organ of Corti. Although intriguing, these findings are only correlative; further studies would be needed to directly address the hypothesis that Notch ligands presented on spiral ganglion neurites contribute to Notch-Hes5 signaling in the organ of Corti.

Recent studies have demonstrated that under certain conditions, neonatal mouse cochlear supporting cells are capable of proliferation and/or differentiation into new hair cells (Chardin and Romand 


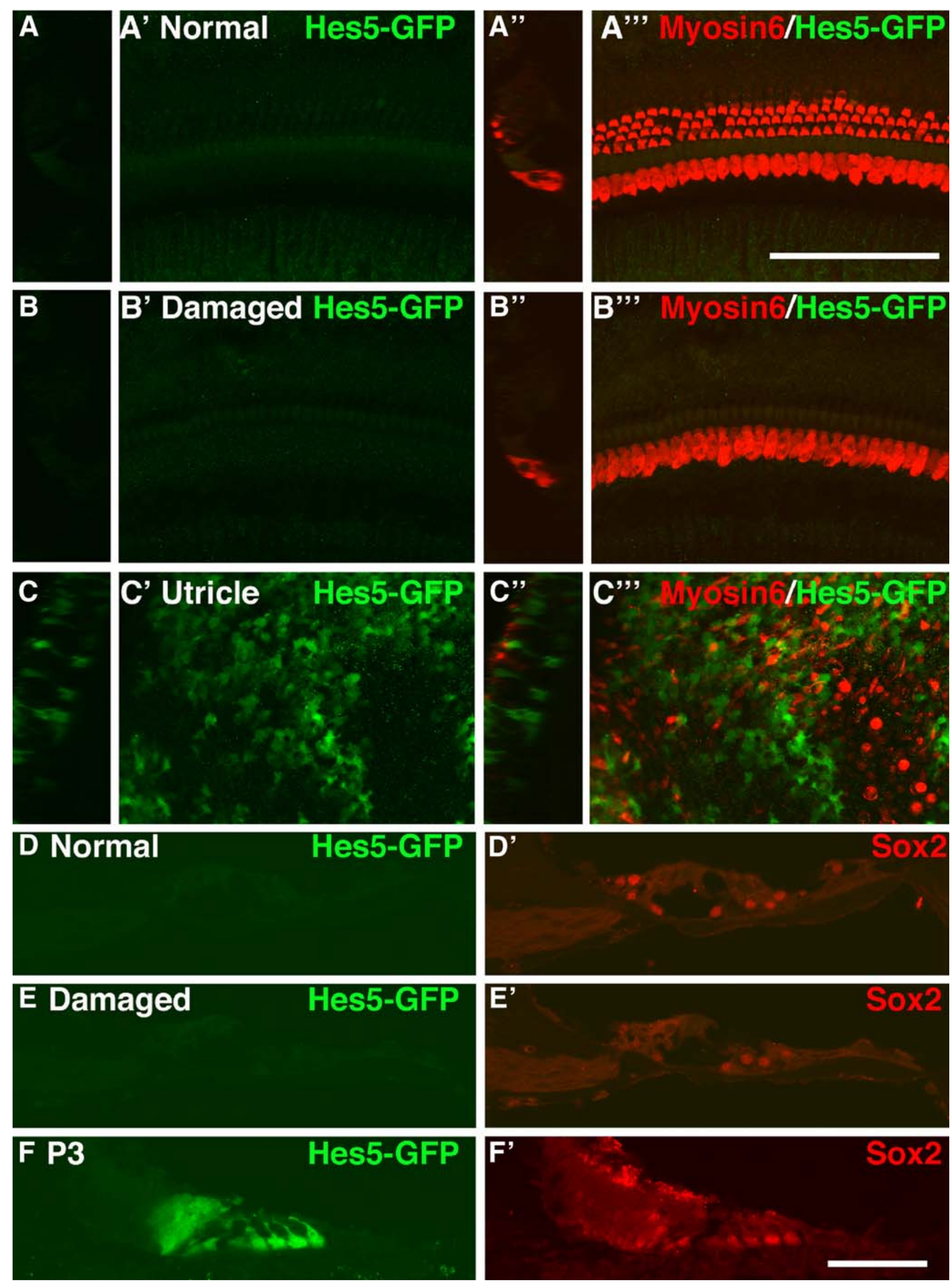


FIG. 6. Hes5-GFP is not upregulated in the adult cochlea after damage. Adult Hes5-GFP mice were given ototoxic injections and sacrificed 2 or 4 days later. Tissues were collected from injected mice and uninjected littermate controls and processed for either whole mount (A-A'"' and $\mathbf{B}-\mathbf{B}^{\prime \prime \prime}$ ) or cryosection (D-D' and $\mathbf{E}-\mathbf{E}^{\prime}$ ) immunohistochemistry alongside positive control tissues: whole mount adult utricles $\left(\mathbf{C}-\mathbf{C}^{\prime \prime \prime}\right)$ or cryosectioned P3 cochlea $\left(\mathbf{E}-\mathbf{E}^{\prime}\right)$. A-A $\mathbf{A}^{\prime \prime \prime}$ Normal adult Hes5-GFP cochlea processed for whole mount immunohistochemistry with antibodies to GFP and Myosin6 shows no expression of Hes5-GFP. ZY plane (A and $\mathbf{A}^{\prime \prime}$ ) and brightest point XY projection views ( $\mathbf{A}^{\prime}$ and $\left.\mathbf{A}^{\prime \prime \prime}\right)$ are shown. The normal arrangement of inner and outer hair cells are seen in the merged views ( $\mathbf{A}^{\prime}$ and $\left.\mathbf{A}^{\prime \prime \prime}\right)$. B-B $\mathbf{B}^{\prime \prime \prime}$ Hes5-GFP is also not expressed in a drug-damaged cochlea 4 days after ototoxic injection, which caused complete outer hair cell loss. C-C'" Hes5-GFP immunolabeling is clearly present in utricle tissue from uninjected animal processed and imaged alongside cochlear tissues in A-A'" and B-B'"'. D-D' A normal adult Hes5-GFP cochlea cryosection was immunolabeled with antibodies to GFP and Sox2. No Hes5-GFP was detected. Anti-Sox2 labeled supporting cell nuclei. E-E' In a drug-damaged adult Hes5-GFP cochlea cryosection, 4 days after injection, GFP was also not detected. However, supporting cells were still present and labeled with anti-Sox2. F-F' A P3 Hes5-GFP cochlear cryosection was processed alongside adult tissues shown in $\mathbf{C}$ and $\mathbf{D}$ and shows strong labeling of Hes5-GFP and Sox2. Scale bar in $\mathbf{A}^{\prime \prime \prime}=100 \mu \mathrm{m}$ and applies to $\mathbf{A}-\mathbf{A}^{\prime \prime \prime}, \mathbf{B}-\mathbf{B}^{\prime \prime \prime}$, and $\mathbf{C}-\mathbf{C}^{\prime \prime \prime}$. Scale bar in $\mathbf{F}^{\prime}=100 \mu \mathrm{m}$ and applies to $\mathbf{D}-\mathbf{D}^{\prime}, \mathbf{E}-\mathbf{E}^{\prime}$, and $\mathbf{F}-\mathbf{F}^{\prime}$

1997; White et al. 2006; Yamamoto et al. 2006; Takebayashi et al. 2007; Doetzlhofer et al. 2009). Inhibition of Notch signaling in cochlear explant cultures with DAPT was shown to lead to transdifferentiation of supporting cells into hair cells as late as P3 (Yamamoto et al. 2006; Takebayashi et al. 2007; Hayashi et al. 2008). Two other recent studies found that cells isolated from neonatal cochleae can be maintained in vitro and can give rise to cells with hair cell characteristics; however, the expression of progenitor markers and the capacity for proliferation of isolated supporting cells decreases dramatically during postnatal development (White et al. 2006; Oshima et al. 2007). These findings indicate that supporting cells retain some degree of plasticity even into the neonatal period and that Notch signaling may have a role in preventing spontaneous cell fate changes. Since loss of Notch-Hes5 signaling in postnatal supporting cells correlates with diminishment of stem cell features, this pathway is a potential candidate for regulation of supporting cell plasticity.

\section{Hes 5 in development of vestibular epithelia}

The pattern of Hes 5 expression in vestibular supporting cells is similar to that of the cochlea and suggests a similar role for this gene in vestibular development, regulating progenitor maintenance and differentiation. Hes 5 null mice, analyzed at birth, were found to have slight increases in hair cell numbers in the utricle and saccule (Zine et al. 2001). The increase in the number of hair cells in the utricle of Hes 5 mutants was relatively greater than the increase observed in the saccule (Zine et al. 2001), which is consistent with our observation that Hes 5 is more broadly expressed in the utricle than the saccule (J and J' in Fig. 4). Hes1 appears to have distinct and overlapping roles with Hes 5 in vestibular development, since loss of either gene alone or together in double heterozygotes leads to production of extra vestibular hair cells (Zine et al. 2001). Although the cristae of Hes 5 mutant mice have not been analyzed, it is reasonable to expect a hair cell overproduction phenotype in the cristae of mice lacking Hes5, given that Hes5 is strongly expressed in the developing cristae.

\section{Hes 5 in adult vestibular supporting cells is correlated with regeneration potential}

We found that Hes 5 expression is maintained in some adult vestibular supporting cells, particularly in the cristae and the utricle (Fig. 5). Previous studies indicate that mammalian vestibular sensory epithelia retain some potential for proliferation and regeneration. Early studies performed in vitro showed that supporting cells in mammalian utricular sensory epithelia proliferate after hair cell loss caused by treatment with the aminoglycosides and new immature hair cells appear after several weeks (Forge et al. 1993; Warchol et al. 1993). It was also found that treatment of cultured adult mouse utricles with mitogenic growth factors stimulates proliferation of supporting cells (Yamashita and Oesterle 1995). More recent in vivo studies in rats and mice show that hair cells spontaneously regenerate in aminoglycosidedamaged utricular sensory epithelia (Oesterle et al. 2003; Kawamoto et al. 2009). Additionally, cells isolated from adult vestibular organs are capable of forming spheres and can give rise to a variety of cell types, including cells with hair cell characteristics ( $\mathrm{Li}$ et al. 2003; Oshima et al. 2007). In addition, significant hair cell regeneration has been show to occur in the chinchilla crista ampullaris following hair cell damage (Tanyeri et al. 1995; Lopez et al. 1997). Interestingly, Lopez et al. reported that hair cells appeared to regenerate first in the peripheral areas of the crista and that type II hair cells, but not type I hair cells, were regenerated. Since we find that Hes5-GFP is highly enriched in the peripheral areas of the cristae where most type II hair cells are found, this result provides further correlation between Hes 5 expression and regenerative capacity. Thus, in sharp contrast to the cochlea, adult mammalian vestibular epithelia exhibit regenerative capacity, which appears to rely on supporting cells with stem cell features. The presence of active Notch-Hes5 signaling in adult vestibular epithelia correlates with maintenance of regenerative capacity in these tissues. This correlation 
needs further evaluation; but it suggests the hypothesis that Hes5-positive supporting cells are endowed with greater regenerative potential than other vestibular supporting cells. Future studies should address this hypothesis directly and investigate the potency of individual supporting cell populations, one of which can now be identified by expression of Hes5-GFP.

\section{Absence of Notch-Hes5 signaling in the damaged mammalian cochlea and implications for regeneration}

Although the adult vestibular epithelium has clear Hes 5 expression, the adult mammalian cochlea lacks Notch-Hes5 signaling. Moreover, Hes5-GFP is not expressed in the adult cochlea even in response to hair cell damage. The apparent lack of Notch signal activity in the adult cochlea could be due to absence of Notch ligand expression in hair cells, which downregulate Delta-like 1 (Dll1) and Dll3 postnatally (Hartman et al. 2007). However, Jag1 is still expressed in the adult cochlea (Oesterle et al. 2008), and Notch1 expression persists through at least P7 (Murata et al. 2006), indicating that key elements of this pathway may be present in the adult cochlea. Future studies will be necessary to resolve this issue.

The absence of Notch signaling in the mature, damaged mammalian organ of Corti may be related to the lack of regeneration in this tissue. Hair cell regeneration in birds and fish has been shown to depend on proliferation and/or direct transdifferentiation of supporting cells (Stone et al. 1999; Roberson et al. 2004), and Notch signaling is active in regenerating sensory epithelia and appears to play a role in regulating the regeneration process. Delta-Notch signaling was shown to be active in the normal chick utricle and becomes upregulated in the basilar papilla during hair cell regeneration (Stone and Rubel 1999). Additionally, Notch signaling was shown to regulate the extent of hair cell regeneration in the zebrafish lateral line (Ma et al. 2008). Similarly, in the regenerating post-hatch chick retina, Notch activity is necessary for the de-differentiation/proliferation of Muller glia (Hayes et al. 2007), while in the central nervous system, Notch has been shown to be required for maintaining progenitors and neural stem cells in development and adults (Alexson et al. 2006; Givogri et al. 2006).

In summary, we showed conclusively that Hes 5 is expressed in discrete populations of supporting cells in the developing mouse inner ear. We found that Hes 5 is downregulated in the cochlea during the first postnatal week, during the period of cochlear maturation and diminishment of stem cell features. In contrast, Hes 5 expression is maintained in adult vestibular sensory epithelia, which are known to retain capacity for proliferation/regeneration. Importantly,
Hes 5 is absent in the normal and drug-damaged adult mammalian cochlea, indicating a failure in Notch signaling, consistent with the lack of regenerative capacity. Since loss of Notch-Hes5 signaling in postnatal supporting cells correlates with diminishment of stem cell features, reactivating this pathway in mature cochlear support cells may provide a means of restoring regenerative capacity.

\section{ACKNOWLEDGMENTS}

The authors thank Dr. Elizabeth Oesterle and Sean Campbell for consultation and help with the drug-damage protocol, Dr. Toshinori Hayashi and Catherine Ray for help optimizing our in situ hybridization method, and Dr. Jennifer Stone for helpful comments. In addition, we are grateful for insightful discussion with members of the Reh and Bermingham-McDonogh labs. This work is supported by the following grants: RO1 EY13475 to T.A.R. sponsored by NIH/ NEI; T32 HD07183-26A1 to B.H.H. sponsored by NIH/ NICHD; and funding from the Hearing Regeneration Initiative to $\mathrm{O} . \mathrm{BMcD}$.

\section{REFERENCES}

Alexson TO, Hitoshi S, Coles BL, Bernstein A, van der Kooy D. Notch signaling is required to maintain all neural stem cell populations - irrespective of spatial or temporal niche. Dev. Neurosci. 28:34-48, 2006.

BASAK O, TAYLOR V. Identification of self-replicating multipotent progenitors in the embryonic nervous system by high Notch activity and Hes5 expression. Eur. J. Neurosci. 25:1006-1022, 2007.

Bermingham-McDonogh O, Rubel EW. Hair cell regeneration: winging our way towards a sound future. Curr. Opin. Neurobiol. 13:119-126, 2003.

Bermingham-McDonogh O, Oesterle EC, Stone JS, Hume CR, Huynh HM, Hayashi T. Expression of Prox1 during mouse cochlear development. J. Comp. Neurol. 496:172-186, 2006.

Brooker R, Hozumi K, Lewis J. Notch ligands with contrasting functions: Jagged1 and Delta1 in the mouse inner ear. Development 133:1277-1286, 2006.

Burgess BJ, Adams JC, Nadol JB, JR. Morphologic evidence for innervation of Deiters' and Hensen's cells in the guinea pig. Hear. Res. 108:74-82, 1997.

CHARdin S, Romand R. Factors modulating supernumerary hair cell production in the postnatal rat cochlea in vitro. Int. J. Dev. Neurosci. 15:497-507, 1997.

Chen P, Johnson JE, Zoghbi HY, Segil N. The role of Math1 in inner ear development: Uncoupling the establishment of the sensory primordium from hair cell fate determination. Development 129:2495-2505, 2002.

Chitnis AB. The role of Notch in lateral inhibition and cell fate specification. Mol. Cell Neurosci. 6:311-321, 1995.

Cornbrooks C, Bland C, Williams DW, Truman JW, Rand MD. Delta expression in post-mitotic neurons identifies distinct subsets of adult-specific lineages in Drosophila. Dev. Neurobiol. 67:23-38, 2007.

Dabdoub A, Puligilla C, Jones JM, Fritzsch B, Cheah KS, Pevny LH, KeLley MW. Sox2 signaling in prosensory domain specification 
and subsequent hair cell differentiation in the developing cochlea. Proc. Natl. Acad. Sci. U. S. A. 105:18396-18401, 2008.

Daudet N, Lewis J. Two contrasting roles for Notch activity in chick inner ear development: specification of prosensory patches and lateral inhibition of hair-cell differentiation. Development 132:541-551, 2005.

Daudet N, Ariza-McNaughton L, Lewis J. Notch signalling is needed to maintain, but not to initiate, the formation of prosensory patches in the chick inner ear. Development 134:2369-2378, 2007.

Dechesne CJ, Rabejac D, Desmadryl G. Development of calretinin immunoreactivity in the mouse inner ear. J. Comp. Neurol. 346:517-529, 1994.

Doetzlhofer A, Basch ML, Ohyama T, Gessler M, Groves AK, Segil $\mathrm{N}$. Hey2 regulation by FGF provides a Notch-independent mechanism for maintaining pillar cell fate in the organ of Corti. Dev. Cell. 16:58-69, 2009.

ECHTELER SM. Developmental segregation in the afferent projections to mammalian auditory hair cells. Proc. Natl. Acad. Sci. U. S. A. 89:6324-6327, 1992.

Fekete DM, Muthukumar S, Karagogeos D. Hair cells and supporting cells share a common progenitor in the avian inner ear. J. Neurosci. 18:7811-7821, 1998.

Forge A. Outer hair cell loss and supporting cell expansion following chronic gentamicin treatment. Hear. Res. 19:171182, 1985.

Forge A, Li L, Corwin JT, Nevill G. Ultrastructural evidence for hair cell regeneration in the mammalian inner ear. Science 259:1616-1619, 1993.

Franklin JL, Berechid Be, Cutting FB, Presente A, Chambers CB, Foltz DR, Ferreira A, NyE JS. Autonomous and non-autonomous regulation of mammalian neurite development by Notch1 and Delta1. Curr Biol. 9:1448-1457, 1999.

Gaiano N, Nye JS, Fishell G. Radial glial identity is promoted by Notch1 signaling in the murine forebrain. Neuron 26:395-404, 2000.

Ge W, Martinowich K, Wu X, He F, Miyamoto A, Fan G, Weinmaster G, SUN YE. Notch signaling promotes astrogliogenesis via direct CSL-mediated glial gene activation. J. Neurosci. Res. 69:848-860, 2002.

Givogri Mi, de Planell M, Galbiati F, Superchi D, Gritti A, Vescovi A, De Veluis J, Bongarzone ER. Notch signaling in astrocytes and neuroblasts of the adult subventricular zone in health and after cortical injury. Dev. Neurosci. 28:81-91, 2006.

Hartman BH, Hayashi T, Nelson BR, Bermingham-McDonogh O, Reh TA. D113 is expressed in developing hair cells in the mammalian cochlea. Dev Dyn. 236:2875-2883, 2007.

Hayashi T, Cunningham D, Bermingham-McDonogh O. Loss of Fgfr3 leads to excess hair cell development in the mouse organ of Corti. Dev. Dyn. 236:525-533, 2007.

Hayashi T, Kokubo H, Hartman BH, Ray CA, Reh TA, BerminghamMcDonogh O. Hesr1 and Hesr2 may act as early effectors of Notch signaling in the developing cochlea. Dev. Biol. 316:87-99, 2008.

Hayes S, Nelson BR, Buckingham B, Reh TA. Notch signaling regulates regeneration in the avian retina. Dev. Biol. 312:300$311,2007$.

Hojo M, Ohtsuka T, Hashimoto N, Gradwohl G, Guillemot F, KAGEYAMA R. Glial cell fate specification modulated by the bHLH gene Hes 5 in mouse retina. Development 127:2515-2522, 2000.

Huang LC, Thorne PR, Housley GD, Montgomery JM. Spatiotemporal definition of neurite outgrowth, refinement and retraction in the developing mouse cochlea. Development 134:2925-2933, 2007.

Hume CR, Bratt DL, Oesterle EC. Expression of LHX3 and SOX2 during mouse inner ear development. Gene Expr. Patterns 7:798-807, 2007.
Jagger DJ, Housley GD. Membrane properties of type II spiral ganglion neurones identified in a neonatal rat cochlear slice. J. Physiol. 552:525-533, 2003.

Kagevama R, Ohtsuka T. The Notch-Hes pathway in mammalian neural development. Cell Res. 9:179-188, 1999.

Kauffman MH. The Atlas of Mouse Development. London, Elsevier Academic, p. 525, 1992.

Kawamoto K, Izumikawa M, Beyer LA, Atkin GM, Raphael Y. Spontaneous hair cell regeneration in the mouse utricle following gentamicin ototoxicity. Hear. Res. 247:17-26, 2009.

Kiernan AE, Ahituv N, Fuchs H, Balling R, Avraham KB, Steel KP, Hrabe de Angelis M. The Notch ligand Jagged1 is required for inner ear sensory development. Proc. Natl. Acad. Sci. U. S. A. 98:3873-3878, 2001.

Kiernan AE, Cordes R, Kopan R, Gossler A, Gridley T. The Notch ligands DLL1 and JAG2 act synergistically to regulate hair cell development in the mammalian inner ear. Development 132:4353-4362, 2005a.

Kiernan Ae, Pelling Al, Leung KK, Tang as, Bell DM, Tease C, Lovell-Badge R, Steel KP, Cheah KS. Sox2 is required for sensory organ development in the mammalian inner ear. Nature 434:1031-1035, 2005b.

Kiernan AE, Xu J, Gridley T. The Notch ligand JAG1 is required for sensory progenitor development in the mammalian inner ear. PLoS Genet. 2:e4, 2006.

Kirjavainen A, Sulg M, Heyd F, Alitalo K, Yla-Herttuala S, Moroy T, Petrova TV, Pirvola U. Prox1 interacts with Atoh1 and Gfil, and regulates cellular differentiation in the inner ear sensory epithelia. Dev. Biol. 322:33-45, 2008.

Lanford PJ, Lan Y, Jiang R, Lindsell C, Weinmaster G, Gridley T, KELLEY MW. Notch signalling pathway mediates hair cell development in mammalian cochlea. Nat. Genet. 21:289-292, 1999.

Lanford PJ, Shailam R, Norton CR, Gridley T, Kelley MW. Expression of Math1 and HES5 in the cochleae of wildtype and Jag2 mutant mice. J. Assoc. Res. Otolaryngol. 1:161-171, 2000.

Lewis AK, Frantz GD, Carpenter Da, de Sauvage fJ, Gao WQ. Distinct expression patterns of notch family receptors and ligands during development of the mammalian inner ear. Mech. Dev. 78:159-163, 1998.

Li H, Liv H, Heller S. Pluripotent stem cells from the adult mouse inner ear. Nat. Med. 9:1293-1299, 2003.

Li S, Mark S, Radde-Gallwitz K, Schlisner R, Chin MT, Chen P. Hey2 functions in parallel with Hesl and Hes 5 for mammalian auditory sensory organ development. BMC Dev. Biol. 8:20, 2008.

Lindsell CE, Boulter J, diSibio G, Gossler A, Weinmaster G. Expression patterns of Jagged, Delta1, Notch1, Notch2, and Notch3 genes identify ligand-receptor pairs that may function in neural development. Mol. Cell Neurosci. 8:14-27, 1996.

Lopez I, Honrubia V, Lee SC, Schoeman G, Beykirch K. Quantification of the process of hair cell loss and recovery in the chinchilla crista ampullaris after gentamicin treatment. Int. J. Dev. Neurosci. 15:447-461, 1997.

LySAKOWSKI A, GOLDBERG JM. Morphology of the vestibular periphery. In: Salvi RJ, Popper AN, Fay RR (eds) The Vestibular System. Springer Handbook of Auditory Research. New York, Springer, 2004.

Ma EY, Rubel EW, Raible DW. Notch signaling regulates the extent of hair cell regeneration in the zebrafish lateral line. J. Neurosci. 28:2261-2273, 2008.

McDowell B, Davies S, Forge A. The effect of gentamicin-induced hair cell loss on the tight junctions of the reticular lamina. Hear. Res. 40:221-232, 1989.

Morrison A, Hodgetts C, Gossler A, Hrabe de Angelis M, Lewis J. Expression of Deltal and Serrate1 (Jagged1) in the mouse inner ear. Mech Dev. 84:169-172, 1999.

Morrison SJ, Perez Se, Qiao Z, Verdi JM, Hicks C, Weinmaster G, ANDERson DJ. Transient Notch activation initiates an irreversible 
switch from neurogenesis to gliogenesis by neural crest stem cells. Cell 101:499-510, 2000.

Murata J, Tokunaga A, Okano H, Kubo T. Mapping of notch activation during cochlear development in mice: implications for determination of prosensory domain and cell fate diversification. J. Comp. Neurol. 497:502-518, 2006.

Nelson BR, Sadhu M, Kasemeier JC, Anderson LW, Lefcort F. Identification of genes regulating sensory neuron genesis and differentiation in the avian dorsal root ganglia. Dev. Dyn. 229:618-629, 2004.

Nelson BR, Hartman BH, Georgi SA, Lan MS, Reh TA. Transient inactivation of Notch signaling synchronizes differentiation of neural progenitor cells. Dev. Biol. 304:479-498, 2007.

Oesterle EC, Stone JS. Hair cell regeneration: mechanisms guiding cellular proliferation and differentiation. In: Salvi RJ, Popper AN, Fay RR (eds) Hair Cell Regeneration, Repair, and Protection. Springer Handbook of Auditory Research. New York, Springer, 2008.

Oesterle EC, Cunningham DE, Westrum LE, Rubel EW. Ultrastructural analysis of $[3 \mathrm{H}]$ thymidine-labeled cells in the rat utricular macula. J. Comp. Neurol. 463:177-195, 2003.

Oesterle EC, Campbell S, Taylor RR, Forge A, Hume CR. Sox2 and JAGGED1 expression in normal and drug-damaged adult mouse inner ear. J. Assoc. Res. Otolaryngol. 9:65-89, 2008.

Ohtsuka T, Ishibashi M, Gradwohl G, Nakanishi S, Guillemot F, Kageyama R. Hes1 and Hes 5 as notch effectors in mammalian neuronal differentiation. Embo J. 18:2196-2207, 1999.

Okamura HO, Shibahara-Maruyama I, Sugai N, Adams JC. Innervation of supporting cells in the guinea pig cochlea detected in blocsurface preparations. Neuroreport 13:1585-1588, 2002.

Oshima K, Grimm CM, Corrales CE, Senn P, Martinez Monedero R, Geleoc GS, Edge A, Holt JR, Heller S. Differential distribution of stem cells in the auditory and vestibular organs of the inner ear. J. Assoc. Res. Otolaryngol. 8:18-31, 2007.

Pickles JO, van Heumen WR. Lateral interactions account for the pattern of the hair cell array in the chick basilar papilla. Hear. Res. 145:65-74, 2000.

PujoL R. Morphology, synaptology and electrophysiology of the developing cochlea. Acta Otolaryngol. Suppl. 421:5-9, 1985.

Raphael Y, Altschuler RA. Reorganization of cytoskeletal and junctional proteins during cochlear hair cell degeneration. Cell Motil. Cytoskelet. 18:215-227, 1991.

Roberson DW, Alosi JA, Cotanche DA. Direct transdifferentiation gives rise to the earliest new hair cells in regenerating avian auditory epithelium. J. Neurosci. Res. 78:461-471, 2004.

Sage C, Venteo S, Jeromin A, Roder J, Dechesne CJ. Distribution of frequenin in the mouse inner ear during development, comparison with other calcium-binding proteins and synaptophysin. Hear. Res. 150:70-82, 2000.

Sestan N, Artavanis-Tsakonas S, Rakic P. Contact-dependent inhibition of cortical neurite growth mediated by notch signaling. Science 286:741-746, 1999.

Shailam R, Lanford PJ, Dolinsky CM, Norton CR, Gridley T, Kelley MW. Expression of proneural and neurogenic genes in the embryonic mammalian vestibular system. J. Neurocytol. 28:809-819, 1999.

Simmons DD. A transient afferent innervation of outer hair cells in the postnatal cochlea. Neuroreport 5:1309-1312, 1994.

Stone JS, Cotanche DA. Hair cell regeneration in the avian auditory epithelium. Int. J. Dev. Biol. 51:633-647, 2007.

Stone JS, Rubel EW. Deltal expression during avian hair cell regeneration. Development 126:961-973, 1999.
Stone JS, Choi YS, Woolley SM, Yamashita H, Rubel EW. Progenitor cell cycling during hair cell regeneration in the vestibular and auditory epithelia of the chick. J. Neurocytol. 28:863-876, 1999.

Takebayashi S, Yamamoto N, Yabe D, Fukuda H, Kojima K, Ito J, Honjo T. Multiple roles of Notch signaling in cochlear development. Dev Biol. 307:165-178, 2007.

Tang LS, Alger HM, Pereira FA. COUP-TFI controls Notch regulation of hair cell and support cell differentiation. Development 133:3683-3693, 2006.

Tanigaki K, Nogaki F, Takahashi J, Tashiro K, Kurooka H, Hono T. Notch1 and Notch3 instructively restrict bFGF-responsive multipotent neural progenitor cells to an astroglial fate. Neuron 29:45-55, 2001.

TANYeri H, Lopez I, Honrubia V. Histological evidence for hair cell regeneration after ototoxic cell destruction with local application of gentamicin in the chinchilla crista ampullaris. Hear. Res. 89:194-202, 1995.

Taylor MK, Yeager K, Morrison SJ. Physiological Notch signaling promotes gliogenesis in the developing peripheral and central nervous systems. Development 134:2435-2447, 2007.

TAylor RR, Nevill G, Forge A. Rapid hair cell loss: a mouse model for cochlear lesions. J. Assoc. Res. Otolaryngol. 9:44-64, 2008.

Tsai H, Hardisty Re, Rhodes C, Kiernan AE, Roby P, TymowskaLalanne Z, Mburu P, Rastan S, Hunter AJ, Brown SD, Steel KP. The mouse slalom mutant demonstrates a role for Jagged 1 in neuroepithelial patterning in the organ of Corti. Hum. Mol. Genet. 10:507-512, 2001.

Warchol Me, Lambert PR, Goldstein BJ, Forge A, Corwin JT. Regenerative proliferation in inner ear sensory epithelia from adult guinea pigs and humans. Science 259:1619-1622, 1993.

White PM, Doetzlhofer A, Lee YS, Groves AK, Segil N. Mammalian cochlear supporting cells can divide and trans-differentiate into hair cells. Nature 441:984-987, 2006.

Woods C, Montcouquiol M, Kelley MW. Math1 regulates development of the sensory epithelium in the mammalian cochlea. Nat. Neurosci. 7:1310-1318, 2004.

Wu WJ, Sha SH, McLaren JD, Kawamoto K, Raphael Y, Schacht J. Aminoglycoside ototoxicity in adult CBA, C57BL and BALB mice and the Sprague-Dawley rat. Hear. Res. 158:165-178, 2001.

Yamamoto N, Tanigaki K, Tsuji M, Yabe D, Ito J, Honjo T. Inhibition of Notch/RBP-J signaling induces hair cell formation in neonate mouse cochleas. J. Mol. Med. 84:37-45, 2006.

Yamashita H, Oesterle EC. Induction of cell proliferation in mammalian inner-ear sensory epithelia by transforming growth factor alpha and epidermal growth factor. Proc. Natl. Acad. Sci. U. S. A. 92:3152-3155, 1995.

Zhang N, Martin GV, Kelley MW, Gridley T. A mutation in the Lunatic fringe gene suppresses the effects of a Jagged2 mutation on inner hair cell development in the cochlea. Curr. Biol. 10:659-662, 2000.

Zheng JL, Shou J, Gullemot F, Kageyama R, Gao WQ. Hes1 is a negative regulator of inner ear hair cell differentiation. Development 127:4551-4560, 2000.

Zine A, VAN DE Water TR, DE RibaupierRe F. Notch signaling regulates the pattern of auditory hair cell differentiation in mammals. Development 127:3373-3383, 2000.

Zine A, Aubert A, Qiu J, Therianos S, Guillemot F, Kageyama R, De Ribaupierre F. Hes1 and Hes5 activities are required for the normal development of the hair cells in the mammalian inner ear. J. Neurosci. 21:4712-4720, 2001. 